María José Legaz
C. Guedes Soares

$\underline{\text { http://dx.doi.org/10.21278/brod73104 }}$

ISSN 0007-215X

eISSN 1845-5859

\title{
EVALUATION OF VARIOUS WAVE ENERGY CONVERTERS IN THE BAY OF CÁDIZ
}

UDC 551.46.09:460.355

Original scientific paper

\begin{abstract}
Summary
The Andalusian Agency of Energy has identified three areas of major interest for harnessing wave energy, in their plan of "Marine Energy and Energy Resources of Andalusia". One of these areas is located on the Atlantic coast, the bay of Cádiz. Considering this initial interest, the objective of this work is to carry out an evaluation of the performance provided by various technologies of wave energy conversion in the bay of Cádiz. The data for the wave climate in the target area are obtained from the Spanish Agency Puertos del Estado. Diagrams for bivariate distributions of the sea states occurrences, defined by the significant wave height and the energy period, are shown. On this basis, the output of nine different technologies for the conversion of wave energy is assessed in the reference locations in the bay of Cádiz. According to the results obtained, it can be said that the bay of Cádiz is a suitable place for wave energy extraction.
\end{abstract}

Key words: Bay of Cádiz; wave energy; WEC

\section{Introduction}

Nowadays, there is a general concern about global warming. Several energy transformations are being studied and tested: solar, wind and marine energy. It seems that marine energy and more specifically wave energy has a high energy density and good predictability. For these reasons, it is stated that wave energy has great potential and a promising future.

The previous attributes make wave energy a good candidate for its utilization as a source of renewable energy. To characterize the ocean wave energy, numerical modelling is one of the most used methods. Guedes Soares et al. [1] has studied various coasts in Europe including the Iberian Peninsula, which was studied in more detail by Silva et al. [2,3]. Studies have also been made in islands, Rusu et al. [4], where a wave prediction system based on WAM and SWAN spectral phase averaging wave models were implemented and tested for Madeira Archipelago. Iglesias and Carballo [5] used the WAM model to assess the wave resource in El Hierro. Rusu and Guedes Soares [6] assessed the wave energy in the Azores Islands in a first step considering remotely sensed and historical data and in a further step based on spectral models. Sierra et al. [7], wave energy re-sources in Lanzarote, is analysed using series of data. Gonçalves et al. [8], the WAVEWATCH III model is used to generate 
waves for the entire North Atlantic basin and the SWAN model is used to determine the transformation of the waves in the Canary Islands. Ponce de León et al., [9] study the wave energy availability in Balearic Sea implementing WAM model and Bernardino et al. [10] used the SWAN model to evaluate the wave energy resources in the Cape Verde Islands.

It is worth mentioning that these models can also be used to study the combined effects of waves and tides using the SWAN model as was done for the coast of Peniche [11] as well as the effect of the wave devices on the wave fields located at the north of Peniche, and in Aguçadora [12, 13].

A study about the estimation of the wave energy potential in Sicily (Italy) was carried out using both buoy wave measurements from Rete Ondametrica Nazionale (RON), the Italian Government wave buoy network, and wave parameter data by ERA-INTERIM, a recent meteorological reanalysis project of the European Centre for Medium-Range Weather Forecasts (ECMWF) can be found in [14]. An assessment of the offshore wave energy potential in the Croatian part of the Adriatic Sea is performed using data taken from World Waves atlas (WWA). WWA is based on satellite measurements, validated against buoy measurements and reanalysed by numerical wave modelling can be seen in [15]. The wave energy resource along the Northern Spanish coast is determined, on hindcast results of WAVEWATCH III for the Atlantic Ocean area, coupled with the SWAN model for the coastal areas, and using surface winds from ECMWF's ERA- Interim data base can be found in [16].

To estimate the energy produced by a wave energy converter (WEC) system in a certain period of time, the most common method is to associate the power matrix of the WEC system to the environmental matrix from the considered area in the determined time interval. This process can be used to evaluate the optimum location of a WEC, but also to identify the most efficient WEC for a given area. After having the wave energy conditions at a given location the performance of different types of wave energy devices have been studied for the Portuguese nearshore [17].

The Andalusian Energy Agency has carried out a study named "Marine Energy and Energy Resources of Andalusia" [18], providing the estimated the harvesting possibilities of clean energy from seas and oceans of the Andalusian Autonomous Community. This report has identified the bay of Cádiz as an interesting area to obtain wave energy.

Based on this fact the objective of this paper is twofold. On the one hand, studying what would be the most appropriate location to install the wave energy converters (WECs) in the bay of Cádiz. On the other hand, studying what is expected from different types of WECs at the different reference locations.

This paper is structured as follows. Section 2, a brief description of the characteristic of the bay of Cádiz and selection of the reference locations is made. Data and parameters of the wave-field in the bay of Cádiz and the scatter diagrams of the reference locations are given in section 3. Section 4 presents the results of the electric power of the different WECs in the reference locations. Section 5, a discussion of the results is made. In section 6, the conclusions are highlighted.

\section{Target area}

The area of interest is the bay of Cádiz. This area has been identified by the Andalusian energy agency as one of the zones with high potential to obtain wave energy, see the report on marine energies, energy resources of Andalusia (Phase I) [18]. 
The bay of Cádiz is located in the province of Cádiz, Andalusia, southwestern in Spain. The coordinates of the province of Cádiz are $36^{\circ} 31$ ' $37.42^{\prime \prime} \mathrm{N}, 6^{\circ} 17^{\prime} 18.95^{\prime \prime} \mathrm{W}$. The province of Cádiz has a population of 1.239.435, according to the Spanish statistical office 2017 [19]. On the other hand, the bay of Cádiz has a high per capita energy consumption compared to the rest of Andalusia, according to the Andalusian energy agency. The primary energy consumption in 2015 was 4.687,7 KTep (Kilo-Ton equivalent of petroleum). Figure 1 shows the location of the Bay of Cádiz with a big red dot

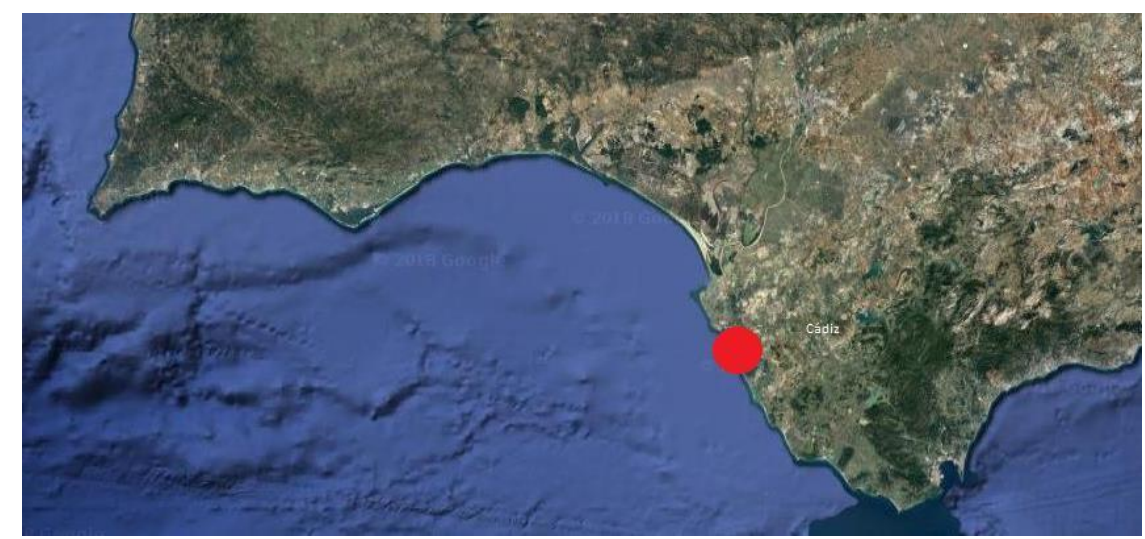

Fig. 1 Bay of Cádiz. Southwestern of Spain.

\subsection{Reference locations}

A wave energy installation could be proposed to meet the energy demand in the bay of Cádiz. Since the wave resource changes with water depth and other characteristics due to the different processes that affect the wavefield during propagation, it is necessary to consider several reference locations. In the environment of the bay of Cádiz has been selected as reference points the two buoy of Cádiz and the SIMAR points that are in line with these buoys.

The reference points are divided in two groups: onshore and offshore points, figures 2 and 3. The offshore points are the Cádiz buoy, and the SIMAR points 5032015, 5034015 and 1054046 and 5026015 shown in table 1 . The coastal points are the Cádiz coastal buoy and the SIMAR 6008050 point, see table 2.

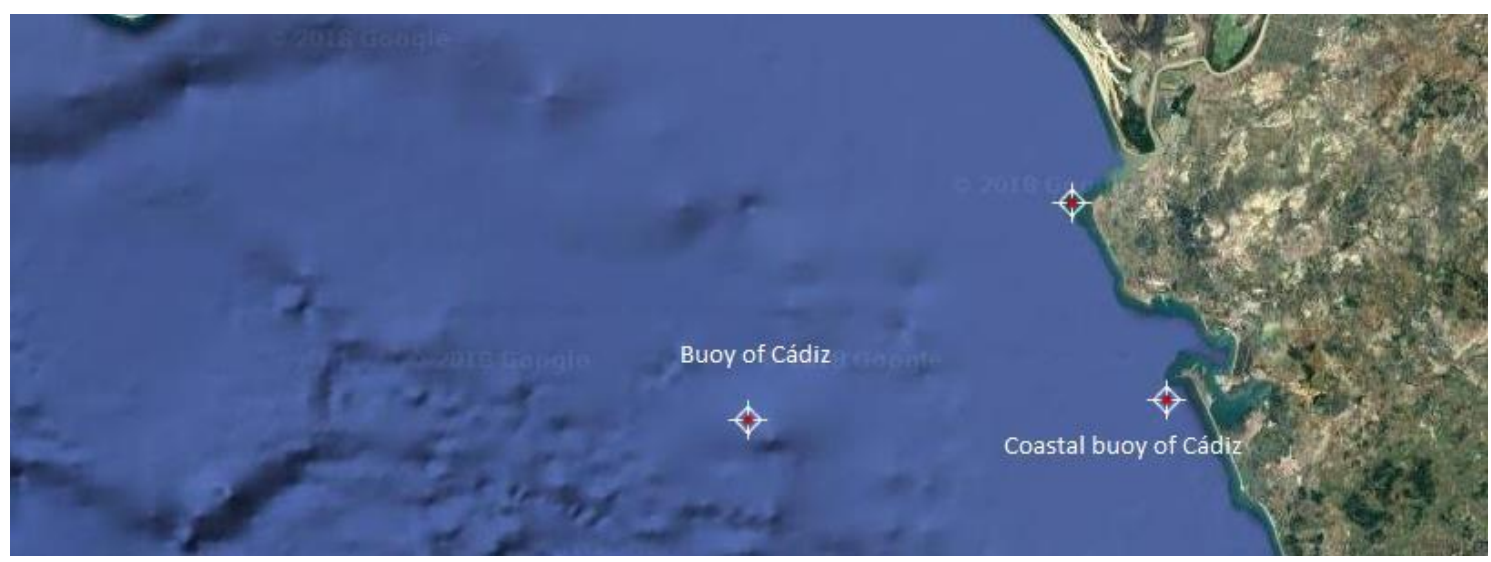

Fig. 2 The buoy of Cádiz and Coastal buoy of Cádiz. Source: Puertos del Estado. 


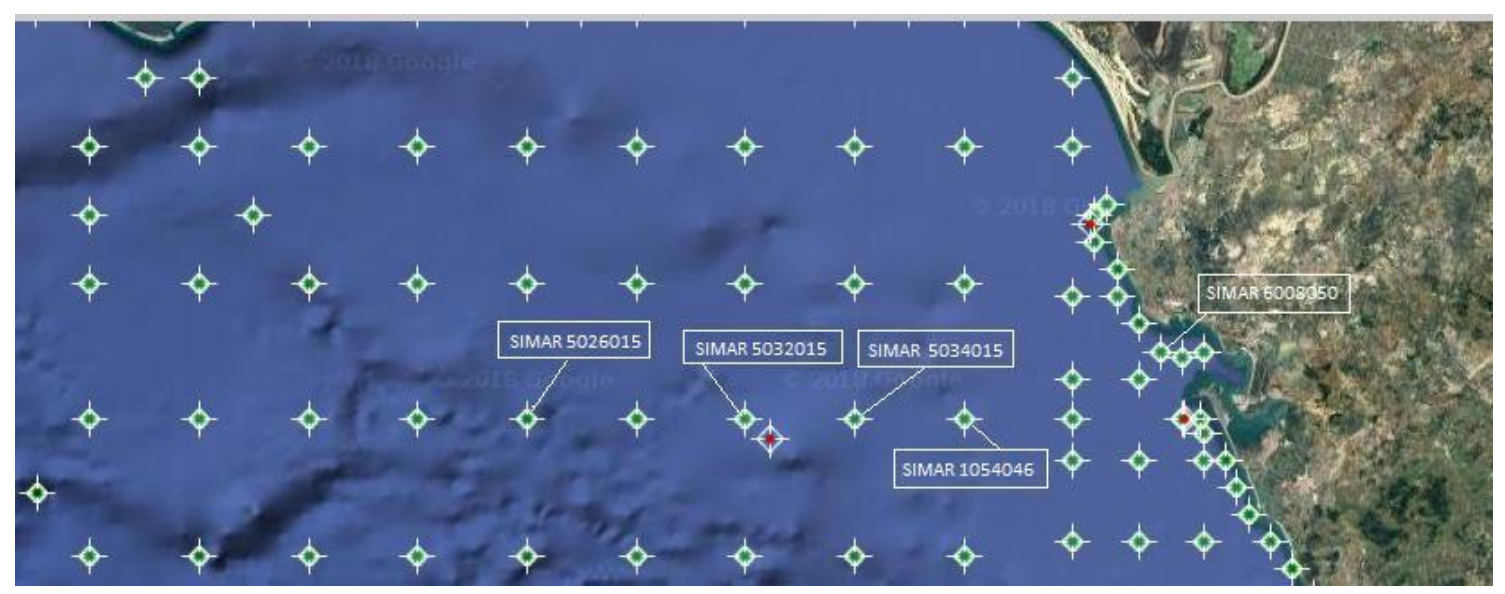

Fig. 3 SIMAR points: 5026015, 5032015, 5034015, 1054046, 6008050. Source: Puertos del Estado.

Table 1 Longitude, latitude, and depth of the Cádiz buoy and the SIMAR offshore points (WAM model). Source: Puertos del Estado.

\begin{tabular}{|c|c|c|}
\hline OFFSHORE POINTS & LONGITUDE & LATITUDE \\
\hline CÁDIZ BUOY & $-6.963 \mathrm{E}$ & $36.477 \mathrm{~N}$ \\
\hline SIMAR 5032015 & $-6.833 \mathrm{E}$ & $36.500 \mathrm{~N}$ \\
\hline SIMAR 5034015 & $-6.667 \mathrm{E}$ & $36.500 \mathrm{~N}$ \\
\hline SIMAR 1054046 & $-6.500 \mathrm{E}$ & $36.500 \mathrm{~N}$ \\
\hline SIMAR 5026015 & $-7.333 \mathrm{E}$ & $36.500 \mathrm{~N}$ \\
\hline
\end{tabular}

Table 2 Longitude, latitude, and depth of the Cádiz coastal buoy and the SIMAR nearshore (WAM model). Source: Puertos del Estado.

\begin{tabular}{|c|c|c|}
\hline NEARSHORE POINTS & LONGITUDE & LATITUDE \\
\hline $\begin{array}{c}\text { COASTAL CÁDIZ } \\
\text { BUOY }\end{array}$ & $-6.330 \mathrm{E}$ & $36.500 \mathrm{~N}$ \\
\hline SIMAR 6008050 & $-6.367 \mathrm{E}$ & $36.583 \mathrm{~N}$ \\
\hline
\end{tabular}

\section{Material and methods}

\subsection{Data and parameters of the wave-field in the bay of Cádiz}

The Spanish Puertos del Estado [20], is a state company in charge of the management of the Spanish state ports. This company carries out the Government's port policy and coordinates and controls the efficiency of the port system, which consists of 28 port authorities that manage the 46 ports of general interest. Puertos del Estado has a web page showing the 
weather forecast in real-time. On the website, there are predictions, real-time data and historical data of waves, wind, currents, salinity and seawater temperature.

To provide reliable information, Puertos del Estado has several buoys located around the Spanish coastline and use mathematical models to obtain information about the waves. From the website of Puertos del Estado, the diagrams $\mathrm{Hs}(\mathrm{m})$ and $\mathrm{Tp}(\mathrm{s})$ for the reference locations have been obtained. These diagrams are used to assess the energy of the waves in the Bay of Cádiz.

Data from different SIMAR points both on the offshore and near the coast are obtained from the website of the Puertos del Estado. The SIMAR data set consists of the time series of wind and wave parameters obtained by numerical modelling. Therefore, they are synthetic data and do not come from direct measures of nature. The SIMAR series arises from the concatenation of the two large groups of numerically modelled wave data that the Puertos del Estado has traditionally counted: SIMAR-44 and WANA. The objective is to be able to offer longer time series in the time interval and updated daily. In this way, the SIMAR set offers information from 1958 until today.

\subsubsection{Cádiz buoys}

In the bay of Cádiz, there are two buoys belong to Puertos del Estado an offshore buoy named Cádiz buoy and an onshore buoy named coastal buoy of Cádiz.

The Cádiz buoy is a SeaWatch [21] type buoy that consists of a stable platform where several instruments can be placed to measure and monitor the marine environment in real time. The buoy is composed of a central part of lenticular form, which provides buoyancy and houses the computer and several electronic equipment, and three masses or vertical supports 6 meters long, located in such a way that half of its length is above the water (providing support for meteorological sensors) and the other half below (housing of oceanographic sensors). The batteries that provide power to the assembly work with solar panel energy. The total length of the buoy (including the sensors) is approximately $6.5 \mathrm{~m}$, its diameter of $1.8 \mathrm{~m}$ and its approximate weight of $600 \mathrm{Kg}$, as in figure 4, on the left. The basic quality control that has been established for all parameters consists in rejecting those that exceed a maximum value and those that present differences with adjacent data greater than a certain threshold. The specific values mentioned have been determined by the experience of each station and parameter. This simple quality control cleans the vast majority of spurious data but does not prevent some abnormal data from being considered correct, so it is convenient to subsequently make a final correction "by hand".

The coastal buoy of Cádiz is a Triaxys type buoy [22] that has a spherical shape of 91 $\mathrm{cm}$ in diameter. It has a water temperature sensor, solid-state accelerometers, a piezo gyroscope and a microprocessor-controlled compass, as in figure 4 on the right. Data processing is carried out on board the buoy using the six motion sensors and the compass. The data analysis is based on the numerical solution of the nonlinear equations of the buoy movement with respect to a fixed reference system. The signal is transmitted by radio to a digital receiver on land, where the various scalar parameters (spectral and zero-crossing) and directional parameters that characterise the sea states are stored in real-time. The wave variables are the result obtained from the application, to the time series of instantaneous elevations, of rigorous quality control prior to the statistical (short term) and spectral (FFT) analysis. The quality control performs verifications aimed at detecting specific errors in the series (peaks, atypical accelerations, anomalous periods, etc.) and of anomalous global behaviours (bias, kurtosis, etc.). The most representative parameters obtained from the analyses are subject to several consistency criteria to try to detect the possible anomalous operation of the measuring equipment. Finally, the results are validated by verifying them by 

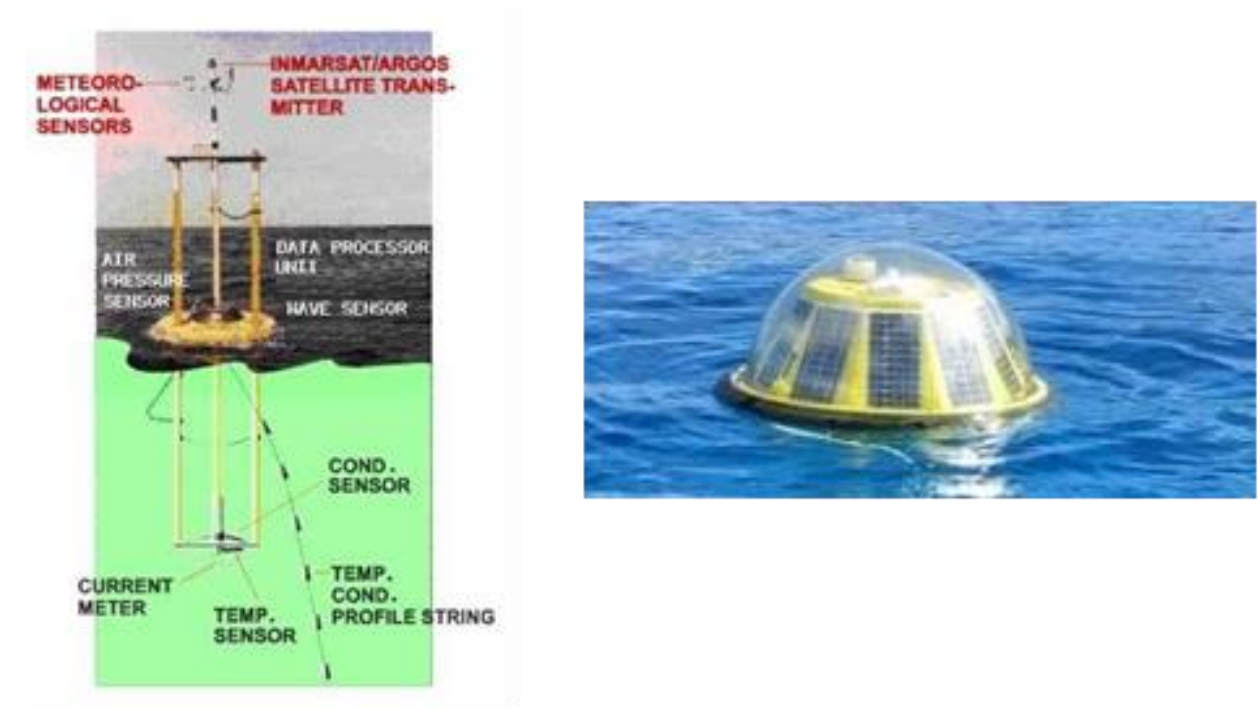

Fig. 4 On the left buoy of Cádiz, on the right coastal buoy of Cádiz. Source: Puertos del Estado.

comparison with other available sources of data as well as by the results of the calibration of the buoy made, after its recovery, in the laboratory.

\subsubsection{Subset SIMAR-44}

The SIMAR-44 set results from a high-resolution analysis of the atmosphere, sea level, and waves that cover the entire Spanish coastal environment. Puertos del Estado simulated the atmosphere and waves in the Mediterranean basin within the framework of the European project HIPOCAS [23]. The wave data in the Atlantic domain and the Strait of Gibraltar come from two independent wind and wave simulations, one conducted by the Puertos del Estado and the other conducted by the Mediterranean Institute for Advanced Studies (IMEDEA) within the framework of the VANIMEDAT-II project. Below is a brief description of how each of the simulated agents was generated.

Mediterranean wind data has been obtained using the REMO regional atmospheric model forced by the data from the NCEP global reanalysis. That reanalysis assimilates instrumental and satellite data. The REMO model has been integrated using a $30^{\prime}$ longitude by $30^{\prime}$ latitude mesh (approximately $50 \mathrm{~km}$ by $50 \mathrm{~km}$ ) with a 5 min time step. The wind data provided are averages per hour at the height of $10 \mathrm{~m}$ above sea level. To obtain wind data in the Atlantic and the Strait of Gibraltar, the RCA 3.5 model is used. This model is fed with reanalysis data obtained from global atmospheric ERA-40. These simulations were performed by the Meteorological Statal Agency [24] with a mesh resolution of $12^{\prime}$ latitude by $12^{\prime}$ longitude (approximately $20 \mathrm{~km}$ by $20 \mathrm{~km}$ ). Due to the resolution of the meshes used in REMO and RCA 3.5 models, it is not possible to model neither the effect of orographic accidents of less than $50 \mathrm{~km}$ nor the influence on the wind of local convective processes modelled. However, the model correctly reproduces regional winds induced by topography such as Cierzo, Tramontana and Mistral. In general, the reproduction of situations with winds from the sea will be more reliable.

To generate the wave fields, the WAM numerical model has been used. This application is a third-generation spectral model that solves the energy balance equation without establishing any prior hypothesis about the shape of the wave spectrum. The data has been 
generated with an hourly rate. A decomposition of the sea of wind and swell has been made. In order to describe situations with swell crossed seas, the possibility of two swell contributions has been considered. For the Mediterranean area, a variable spacing mesh has been used with a resolution of $15^{\prime}$ of latitude x 15' of longitude (approximately $25 \mathrm{~km} \mathrm{x} 25$ $\mathrm{km}$ ) for the east edge of the mesh and 7.5' of latitude x 7.5' of longitude (approximately 12.5 $\mathrm{km} \times 12.5 \mathrm{~km}$ ) for the rest of the modelled area.

On the other hand, a variable spacing mesh covering the entire North Atlantic has been used for the Atlantic area with a resolution of $30^{\prime}$ latitude $\mathrm{x} 30^{\prime}$ longitude for the areas furthest from the Iberian Peninsula, and the Canary Islands increases to $15^{\prime}$ latitude x $15^{\prime}$ longitude when approaching. For the surroundings of the Gulf of Cadiz, the Strait of Gibraltar and the Canary Islands, secondary meshes have been nested to the main mesh with a resolution that reaches $5^{\prime}$ longitude $\times 5^{\prime}$ latitude. The WAM model used to generate this data includes refraction and wave shoaling effects. However, given the resolution of the model, the wave shoaling effects can be considered negligible. Therefore, for practical use, wave data should always be interpreted as data in open water at infinite depths.

\subsubsection{Subset WANA}

The WANA series come from the sea state prediction system that Puertos del Estado [20] has developed in collaboration with the Meteorological Statal Agency (AEMET) [24]. However, WANA data is not prediction data, but diagnostic or analysis data. This means that for each moment, the model provides wind and pressure fields consistent with the previous evolution of the modelled parameters and consistent with the observations made. It is important to note that the wind and wave time series of the WANA set is not homogeneous since wind and wave models are periodically modified to introduce improvements. These improvements have allowed, among other things, to increase the spatial and temporal resolution of the data from which the WANA set information is generated. Below is a brief description of how each of the simulated agents was generated.

The atmospheric model used to generate the wind fields is the HIRLAM (High Resolution Limited Area Model) [25], from AEMET [24]. This is a mesoscale and hydrostatic atmospheric model. The wind data provided is 10 meters high above sea level. The wind data do not reproduce geographic effects or temporal processes of scales lower than the resolution with which the atmosphere model has been integrated. However, the model correctly reproduces the regional winds induced by topography such as Cierzo, Tramontana and Mistral.

To generate the wave fields, two models have been used: WAM and WaveWatch, fed by the wind fields of the HIRLAM model. Both are third-generation spectral models that solve the energy balance equation without establishing any a priori hypothesis about the shape of the wave spectrum. The spatial resolution of the models varies depending on the area since specific applications have been developed for different areas: Atlantic, Mediterranean, Cantabrian, Cadiz, Canary Islands and Strait of Gibraltar. A decomposition of wind and swell has been carried out. In order to describe situations with crossed swells, two possible contributions to the swell have been considered. It is important to keep in mind that, regardless of the coordinate assigned to a WANA node, wave data should always be considered as data in open water and indefinite depths.

WAM wave generation model integrates the basic transport equation. This equation describes the evolution of a two-dimensional ocean wave spectrum without additional assumptions regarding the spectral shape.

The model was developed by a broad number of researchers from different institutions (WAMDI group), following 'Sea Wave Modeling Project' recommendations. One of the aims 
of the group was to develop an operational version of the model at the European Centre for Medium Range Weather Forecasts (ECMWF). This was achieved in 1992. In 1996 Puertos del Estado joined the group and has collaborated in different aspects of the work done. The group final report was released in 1994. Puertos del Estado developed and implemented a two-way nesting procedure in the model for the Spanish Coast.

Using this system, the equation is integrated in the same time step for all points. Since it is possible to define the spacing depending on the grid point location, it works as a variable spacing schema. The resolution is enhanced using intermediate grids, which are placed between the coarse and the fine grids. The version of the WAM model, the distribution of grids has changed. The deep water WAM model is run for the Atlantic-Mediterranean domains, therefore the shallow water effects are not performed. Nested to this domains, specific applications have been developed for the Peninsula, Canary and Balearic Islands domains. All these latter applications use the shallow water version of the WAM model; therefore, refraction and attenuation effects are considered for those (few) grind points located in swallow waters.

The regional scale grid (Atlantic-Mediterranean) use ECMWF HRES model wind forcings, whereas the rest of the applications, given that they are within the AEMET HARMONIE spatial coverage, are forced with this model. Since HARMONIE model forecast length is 48 hours, HRES model is used for the last hours to extend this length until $72 \mathrm{~h}$.

The model produces the wave directional spectra for each grid point. Then, it is used to obtain further information, i.e.: Hs, Tp, Tm, mean direction, wind sea and swell components, etc.

The WAVEWATCH model solves the wave action balance equation in the presence of currents.

The nested WAVEWATCH application covers the Strait of Gibraltar with a resolution of $1 \mathrm{~min}$ and receives boundary conditions from both, the Mediterranean and the Atlantic applications.

With this scheme, combining the two-way nesting procedure with local nested grids, the Spanish coast is covered with at least a resolution of $5 \mathrm{~min}$ with the ocean system. This resolution is further increased by the local system in which the different local applications have a resolution between 200 and $500 \mathrm{~m}$. The ocean wave forecast system is operated on a twice a day cycle, and the results, maps, time series and tables can be looked up at the Spanish Meteorological Service web page, www.inm.es, which is open and free for all users. The forecast results are verified on real time using the data from Puertos del Estado buoy network. The results from this real time verification process are shown at the same web page, so the users are able to get a hold of both, the forecast itself as well as the accuracy of the previous days forecast cycles.

\subsubsection{Scatter diagrams of the reference locations}

Scatter diagrams are summarizing the wave climate and are typically representing the joint probability of wave height, wave period combinations during the period they are encompassing. Figures 5 and 6 show the scatter diagram, the joint distribution of significant wave height (Hs) and the peak period (Tp), in \%, for the reference locations. Data have been obtained from the website of Puertos del Estado for the buoy of Cádiz, coastal buoy of Cádiz and different SIMAR points. Each bin of the graph represents the joint probability, in \%, of a specific state Hs-Tp. Hs (significant height) bins are defined in $0.5 \mathrm{~m}$. intervals were ranging from 0 to 6 meters. Tp (peak period) bins are defined in $1.0 \mathrm{~s}$. intervals were ranging from 0 
to 11 seconds. The colour of each bin represents the number of occurrences expressed in percentage of all observations.

For the Cadiz buoy, the highest value of the joint distribution, superior to $8 \%$ is obtained for $\mathrm{Tp}=5 \mathrm{~s}$ and $\mathrm{Hs}=1 \mathrm{~m}$ (Fig. 5). For 5026015 SIMAR point, the highest value of the joint distribution, about $11 \%$ is obtained for $\mathrm{Tp}=11 \mathrm{~s}$ and $\mathrm{Hs}=1.5 \mathrm{~m}$ (Fig. 5). For 1054046 SIMAR point, the highest value of the joint distribution, about $11 \%$ is obtained for $\mathrm{Tp}=5 \mathrm{~s}$ and $\mathrm{Hs}=1 \mathrm{~m}$ (Fig. 5). For 5032015 SIMAR point, the highest value of the joint distribution, about $11 \%$ is obtained for $\mathrm{Tp}=5 \mathrm{~s}$ and $\mathrm{Hs}=1.5 \mathrm{~m}$ (Fig. 5). For 5034015 SIMAR point, the highest value of the joint distribution, about $11 \%$ is obtained for $\mathrm{Tp}=11 \mathrm{~s}$ and $\mathrm{Hs}=1.3 \mathrm{~m}$ (Fig. 5).

The period of study has been five-year time interval January 2010-December 2014. The significant height, $\mathrm{Hs}$, is one of the most widely used parameters of waves, represents the height of waves that a trained observer would determine with the naked eye from an observation position. It is accepted to be equivalent to the mean value of the $1 / 3 \mathrm{rd}$ highest waves recorded in the measuring interval. The mean period, Tm, describes the mean value of the period from the waves recorded in the measuring interval. The peak period, Tp, is the period of the most energetic group of waves. The more regular are waves, the more Tp and Tm look alike, though usually, Tp is bigger than Tm. The power matrix of a WEC is given in function of the peak period Tp, or mean period Te.

In general, the instrumentation does not provide the wave features with the form of Te. It can be estimated based on $\mathrm{Tp}$ as [25]:

$$
\mathrm{Te}=\alpha \mathrm{Tp},
$$

The coefficient $\alpha$ depends on the shape of the wave spectrum. In assessing the wave energy resource in southern New England, Hageman [26], assumed that $T e=T p$. In this study, the same assumption was adopted when necessary.

\subsection{Wave energy conversion technologies}

From the point of view of wave energy, the energy is divided into two groups, potential and kinetic energy components [27]. Over the years, the WECs designers have had tried to transform the wave energies into electrical energy. The first patented WEC was registered in 1799 in France. Since then, until now, more than 1000 devices have been patented with different mechanisms to transform wave energy in electric energy [28]. The WECs can be classified according to water depth and location of application, type, and size of the considered WEC and working principle in which wave energy can be absorbed [29].

According to location, the WECs can be classified as shoreline, near-shore and deepwater offshore. Shoreline WECs are placed near to the utility network. This location has the disadvantage of the wave are attenuated as they travel through shallow water, so their energy decreases. Nearshore devices are put in shallow water; the disadvantage also is the reduction of wave power, limiting the harvesting potential. Offshore WECs are placed in deep water.

Considering type and size [30, 29], the devices can be categorized as line absorbers and point absorbers. The line absorbers are those in which their horizontal direction is comparable or larger than typical wavelengths; these can be attenuator or terminator. The attenuator is the one in which the larger horizontal dimension of the WEC is parallel to the wave propagation direction. The terminator is the one in which the wave propagation is normal compared to the longer horizontal direction of the WEC. Point absorbers WECs are those in which horizontal dimensions are small compared to the wavelength of the incident waves. 
Within the categories identified above, there is a further level of classification of devices, determined by their mode of operation. For this work, several WECs have been selected. This WECs belong to different categories and are representative of a variety of sizes and working principles. These WECs are Wave Dragon, Pelamis, Aqua Buoy, Archimedes Wave Swing, Langlee, Oceantec, OE Buoy, Pontoon, Seabased AB, Wavebob and SSG.

Wave Dragon is an overtopping WEC. This WEC gets the wave by mean a pair of large curved reflectors, the wave is gathered into the central receiving part. From this central part, the waves flow up a ramp and over the top into a raised reservoir. The water re-turns to the sea through several low-head turbines.

Pelamis is an attenuator WEC. It is a floating device form of cylindrical hollow steel segments connected to each other by two degrees of freedom hinged joints. Each hinged joint is like a universal joint. The central unit of each joint has a system of power conversion. The cylinders operate like pumps; they drive fluid through a hydraulic motor. These hydraulic motor drives an electrical generator.

Aqua Buoy is a point absorber WEC. It is formed by a floater, providing buoyancy to the system. The floater is joined to a large cylinder, called the accelerator tube. The accelerator tube is opened to ingress water on both sides. The accelerator tube has a piston in the center, and this is joined to the top and the bottom section of the buoy by a hose pump, which is made of semi-elastic material. The system is designed in such a way that the natural that the natural frequencies of the piston and the buoy are different, resulting in significant relative motions between the two. This stretch or compress the hose pump. The water in the pump is driving by a system of check valves, through a hydraulic system that terminates into a Pelton turbine. This turbine is that it generates electricity.

AWS (Archimedes Wave Swing) is a point absorber WEC. AWS is totally submerged. This device uses the pressure difference between wave crests and troughs. It consists of a sea bed fixed air-filled cylindrical chamber with a moveable upper cylinder. When a crest goes over the WEC, the water pressure above the device compresses the air within the cylinder, moving the upper cylinder down. When a trough goes over, the water pressure on the device reduces, and the upper cylinder rises. When a crest goes over the WEC, the water pressure above the device compresses the air within the cylinder, moving the upper cylinder down. When a trough goes over, the water pressure on the device reduces, and the upper cylinder rises.

Langlee is an oscillating wave surge converter. Its function is to extract the kinetic energy of the water particles of the waves. This is achieved by a number of hinged flaps located under the water surface. It consists of a pair of working flaps that are placed symmetrically opposing each other; both installed on a moored floating frame (a semisubmerged steel structure).

Oceantec is a point absorber WEC. Its working principle is based on the oscillating water column. It is formed of interacting bodies, so that energy is extracted from its relative movement. This system requires the existence of bearing and guidance elements to guide the movement of one body along with another.

OE Buoy is a water column WEC. This consists of a single air chamber and is free to move in six degrees of freedom. The water column has a submerged opening aligned downstream of the incident wave propagation direction. An oscillating pressure in the chamber and airflow through the turbine is generated by the motion of the water column relative to the oscillating water column body. The system also has a relief valve in order to keep the pressure in the air chamber within acceptable limits. The power conversion is provided by means of an air turbine connected to an electric generator. 
Pontoon is a multibody floating WEC. It consists of many heaving buoys jointed to a submerged reference structure. This structure consists of an arrangement of a single sup-port structure and a series of ballasts baskets, jointed by tension wires. A balance of forces is made by the total buoyancy forces form the buoys and the net gravity forces of the bridge and the ballast baskets. This system uses a hydraulic power take-off system to convert energy.
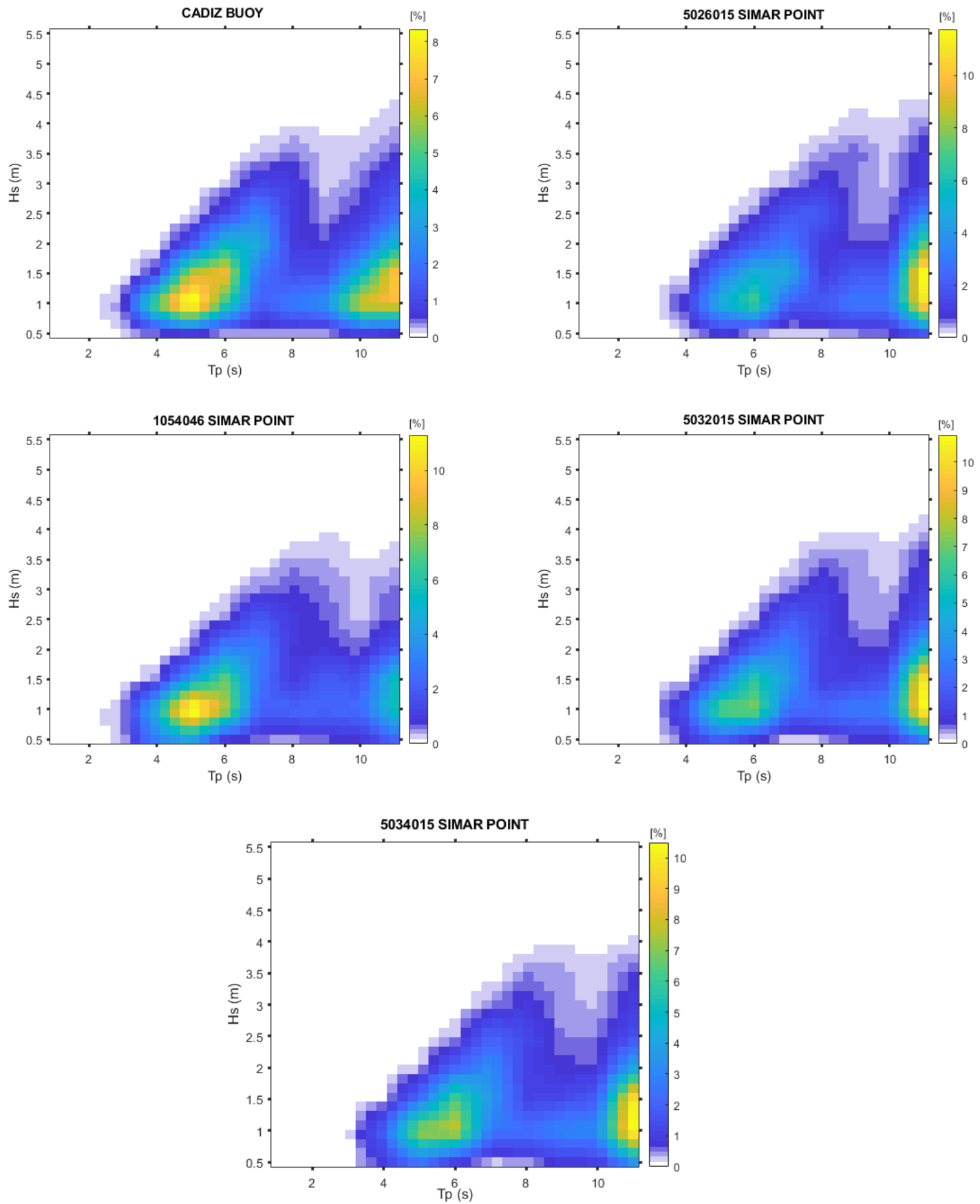

Fig. 5 On the left scatter diagram of buoy of Cádiz and 1054046 SIMAR point for the five-year time interval 2010 to 2014. On the right scatter diagram of 5026015, 5032015 SIMAR points for the five-year time interval 2010 to 2014. In the middle, scatter diagram of 5034015 SIMAR point for the five-year time interval 2010 to 2014. Source: Adapted from Puertos del Estado. 

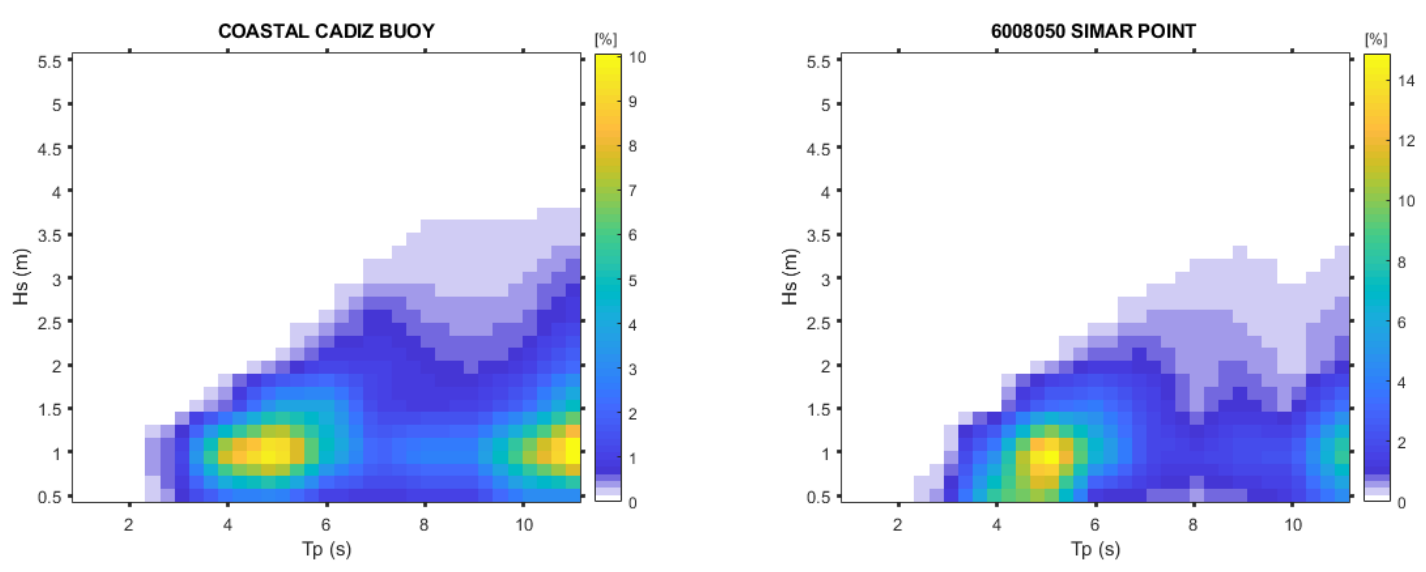

Fig. 6 On the left scatter diagram of coastal buoy of Cádiz for the five-year time interval 2010 to 2014. On the right scatter diagram of 6008050 SIMAR point for the five-year time interval 2010 to 2014. Source: Adapted from Puertos del Estado.

Oyster is formed by a system that comprises a buoyant flap, hinged at its base to a subframe which is pinned to the sea bed using tensioned anchors. The surge component in the waves forces the flap to oscillate which in turn compresses and extends two hydraulic cylinders mounted between the flap and the sub-frame which pumps water at high pressure through a pipeline back to the beach.

Wavebob is classified as a point absorber WEC. This device utilizes the lift and fall of the ocean wave to move the generators. It is formed by two oscillating structures. These structures are directed by a damping system that can respond to predicted wave height, wave power, and frequency. It has a semi-submerged body, the tank structure, which uses captured seawater mass as its inertial mass.

The SSG (Sea Slot-cone Generator) is a wave energy converter of the overtopping type. The structure consists of a number of reservoirs one on the top of each other above the mean water level in which the water of incoming waves is stored temporarily. In each reservoir, expressively designed low head hydro turbine is converting the potential energy of the stored water into power. The key to success for the SSG will be the low cost of the structure and its robustness.

The power matrix of the different system of WECs can be found in different research works, such as [31] and [32]. In the appendix the tables of the power matrix of the different WECs are shown.

\section{Results}

The most appropriate WECs for a specific area are those that have maximum efficiency in the ranges of $\mathrm{Hs}$ and $\mathrm{Te}$, that provide the bulk of occurrences of the waves. The performance of a WECs is provided in tables showing the expected power output (power matrix) for the different pairs of significant wave height and wave period.

To estimate the energy produced by a WEC system in a certain period of time, the most common method is to associate the power matrix of the WEC system to the environment matrix (scatter diagram) of a reference location in the determined time interval. This can be done using the equation. 


$$
P_{E}=\frac{1}{100} \cdot \sum \sum p_{i j} \cdot P_{i j}
$$

where $p i j$ is the energy percentage corresponding to the cell defined by line $i$ and the column $j$ in the environmental matrix (scatter diagram), while $P i j$ is the electric power reported by the WEC system (power matrix) in the same cell.

Table 3, represents the average electric energy production in $\mathrm{kW}$ of different types of WECs: Pelamis, Aqua Buoy, AWS, Langlee, Oceantec, Pontoon, OE Buoy, Wavebob and Wave Dragon in the different offshore reference localizations: Cádiz buoy and SIMAR points 5032015, 5034015,1054046 and 5026015.

Table 4 represents the average electric energy production in $\mathrm{kW}$ of different types of WECs: AWS, Langlee, Oceantec, Oyster, OE Buoy, Wavebob, Wave Dragon and SSG, in the different nearshore reference localizations: Cádiz coastal buoy and SIMAR point 6008050 .

Table 3. Average electric power in $\mathrm{kW}$ for five offshore reference points in the bay of Cádiz, estimations corresponding to the characteristics of nine WEC devices.

\begin{tabular}{|c|r|r|r|r|r|}
\hline \multicolumn{7}{|c|}{ Average Electric Power (in kW) } \\
\hline \multicolumn{7}{|c|}{ POINTS } \\
\hline WECs & $\begin{array}{r}\text { CÁDIZ } \\
\text { BUOY }\end{array}$ & $\begin{array}{r}\text { SIMAR } \\
\mathbf{5 0 3 2 0 1 5}\end{array}$ & $\begin{array}{r}\text { SIMAR } \\
\mathbf{5 0 3 4 0 1 5}\end{array}$ & $\begin{array}{r}\text { SIMAR } \\
\mathbf{1 0 5 4 0 4 6}\end{array}$ & $\begin{array}{r}\text { SIMAR } \\
\mathbf{5 0 2 6 0 1 5}\end{array}$ \\
\hline PELAMIS & 73.9 & 74.5 & 69.8 & 61.3 & 84.2 \\
\hline AQUA BUOY & 22.0 & 37.9 & 21.9 & 17.7 & 28.2 \\
\hline AWS & 124.7 & 140.6 & 128.9 & 110.5 & 171.7 \\
\hline LANGLEE & 80.0 & 75.9 & 72.3 & 70.1 & 81.1 \\
\hline OCEANTEC & 110.8 & 109.3 & 105.0 & 101.1 & 115.2 \\
\hline PONTOON & 202.2 & 198.4 & 188.5 & 182.6 & 216.9 \\
\hline OE BUOY & 111.6 & 117.2 & 108.8 & 92.1 & 136.6 \\
\hline WAVEBOB & 78.5 & 83.1 & 77.1 & 62.0 & 98.1 \\
\hline WAVEDRAGON & 342.1 & 1143.6 & 1043.5 & 837.3 & 1328.7 \\
& & & & & \\
\hline
\end{tabular}

Regarding offshore devices, it can be observed (table 3) that for the converters Pelamis, AWS, Langlee, Oceantec, Pontoon, OE Buoy, Wavebob and Wave Dragon the optimal energetic distribution occurs in location 5026015 SIMAR point. The electric power expected in this location is $84.2 \mathrm{~kW}$ for Pelamis, $171.1 \mathrm{~kW}$ for AWS, $81.1 \mathrm{~kW}$ for Langlee, $115.2 \mathrm{~kW}$ for Oceantec, $216.9 \mathrm{~kW}$ for Pontoon, $136.6 \mathrm{~kW}$ for OE Buoy, $98.1 \mathrm{~kW}$ for Wavebob and $1328.7 \mathrm{~kW}$ for Wave Dragon.

Passing now to the nearshore devices (table 4), it can be observed that for the converters considered, the optimal energetic distribution occurs in location Cadiz coastal buoy. The electric power expected in this location is $85.4 \mathrm{~kW}$ for AWS, $49 \mathrm{~kW}$ for Langlee, $60 \mathrm{~kW}$ for Oceantec, $57.02 \mathrm{~kW}$ for Oyster, $71.3 \mathrm{~kW}$ for OE Buoy, $52.7 \mathrm{~kW}$ for Wavebob, $676.4 \mathrm{~kW}$ for Wave Dragon and $1045.9 \mathrm{~kW}$ for SSG. 
Table 4. Average electric power in $\mathrm{kW}$ for two onshore reference points in the bay of Cádiz, estimations corresponding to the characteristics of eight WEC devices.

\begin{tabular}{|c|c|c|}
\hline \multicolumn{3}{|c|}{ Average Electric Power (in kW) } \\
\hline \multicolumn{2}{|c|}{ POINTS } \\
\hline WECs & C. COASTAL B & SIMAR 6008050 \\
\hline AWS & 85.4 & 59.3 \\
\hline LANGLEE & 49.0 & 41.4 \\
\hline OCEANTEC & 60.0 & 52.0 \\
\hline OYSTER & 57.02 & 45.2 \\
\hline OE BUOY & 71.3 & 54.3 \\
\hline WAVEBOB & 52.7 & 39.2 \\
\hline WAVE DRAGON & 676.4 & 525.9 \\
\hline SSG & 1045.9 & 820.7 \\
\hline
\end{tabular}

In order to provide a more comprehensive picture of the geographical variations of the electric power estimated for each wave energy converter considered, the non-dimensional normalized wave power $\left(P_{E n}\right)$ was evaluated separately for each device in the reference points considered. Thus, the figure 7 illustrates the normalized electric energy provided by the offshore devices (Pelamis, Aqua Buoy and Langlee) in the reference points. Similar representations are illustrated in the figure 8 for Oceantec, Pontoon and OE Buoy. And the figure 9 for Wavebob and Wave Dragon. Figure10 shows the normalized electric energy provided by the onshore devices (AWS, Langlee, Oceantec, Oyster, OE Buoy, Wavebob, Wave Dragon and SSG).

The normalized wave power is expressed as:

$$
P_{E n}=\frac{P_{E}}{P_{E T \max }}
$$

in which $P_{E}$ is the estimated electric power in the respective location for the device considered; and $P_{E T \text { max }}$ represents the maximum value from all the geographical locations estimated for total time for the same device. 


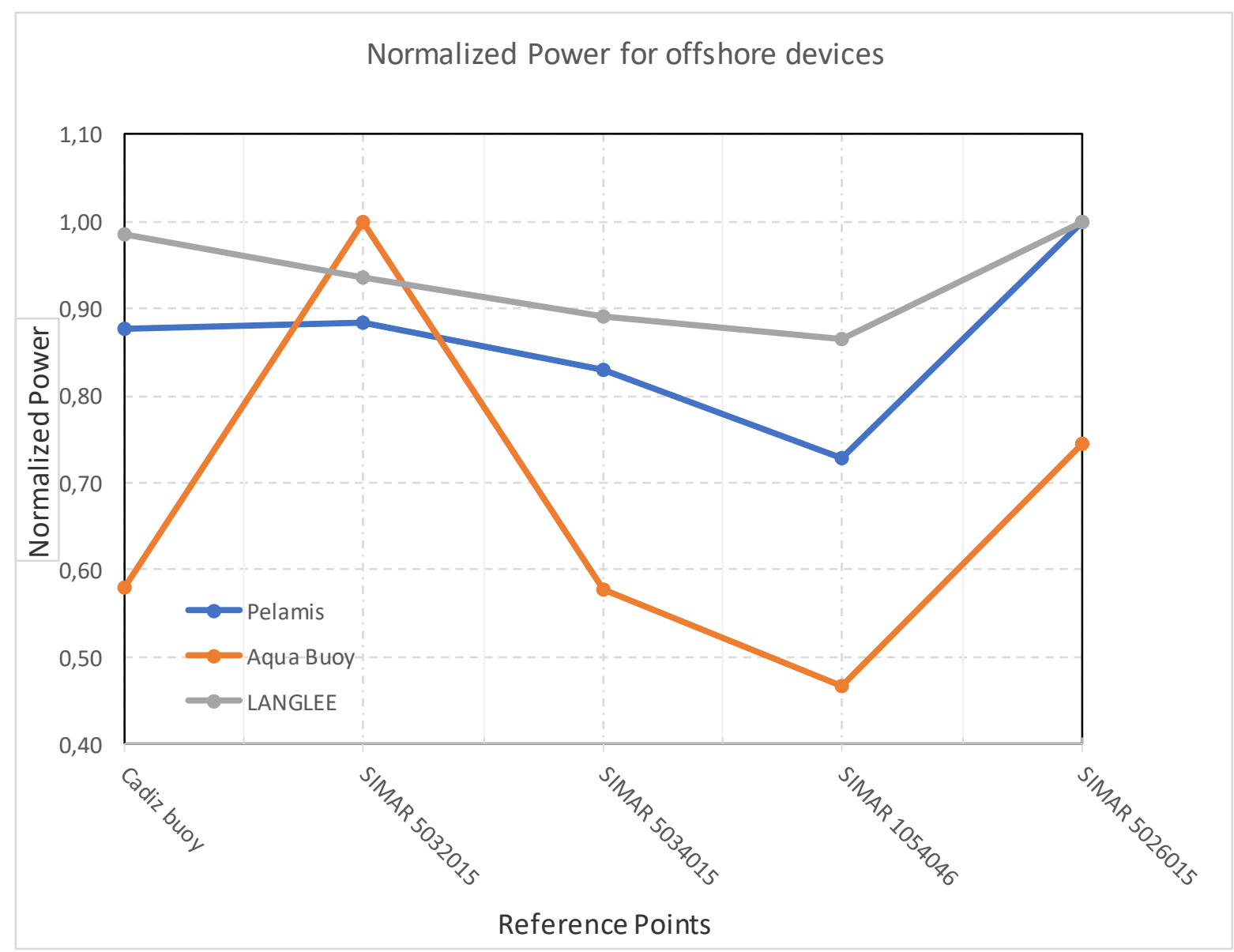

Fig. 7 Normalized electric power for the offshore devices, Pelamis, Aqua Buoy and Langlee in the reference points.

For Aqua Buoy the locations SIMAR 1054046 and SIMAR 5034015 appear to be the less energetic while the location SIMAR 5032015 is the most energetic. For Pelamis and Langlee the locations SIMAR 1054046 and SIMAR 5034015 appear to be also the less energetic while the location SIMAR 5026015 is the most energetic (figure 7). 


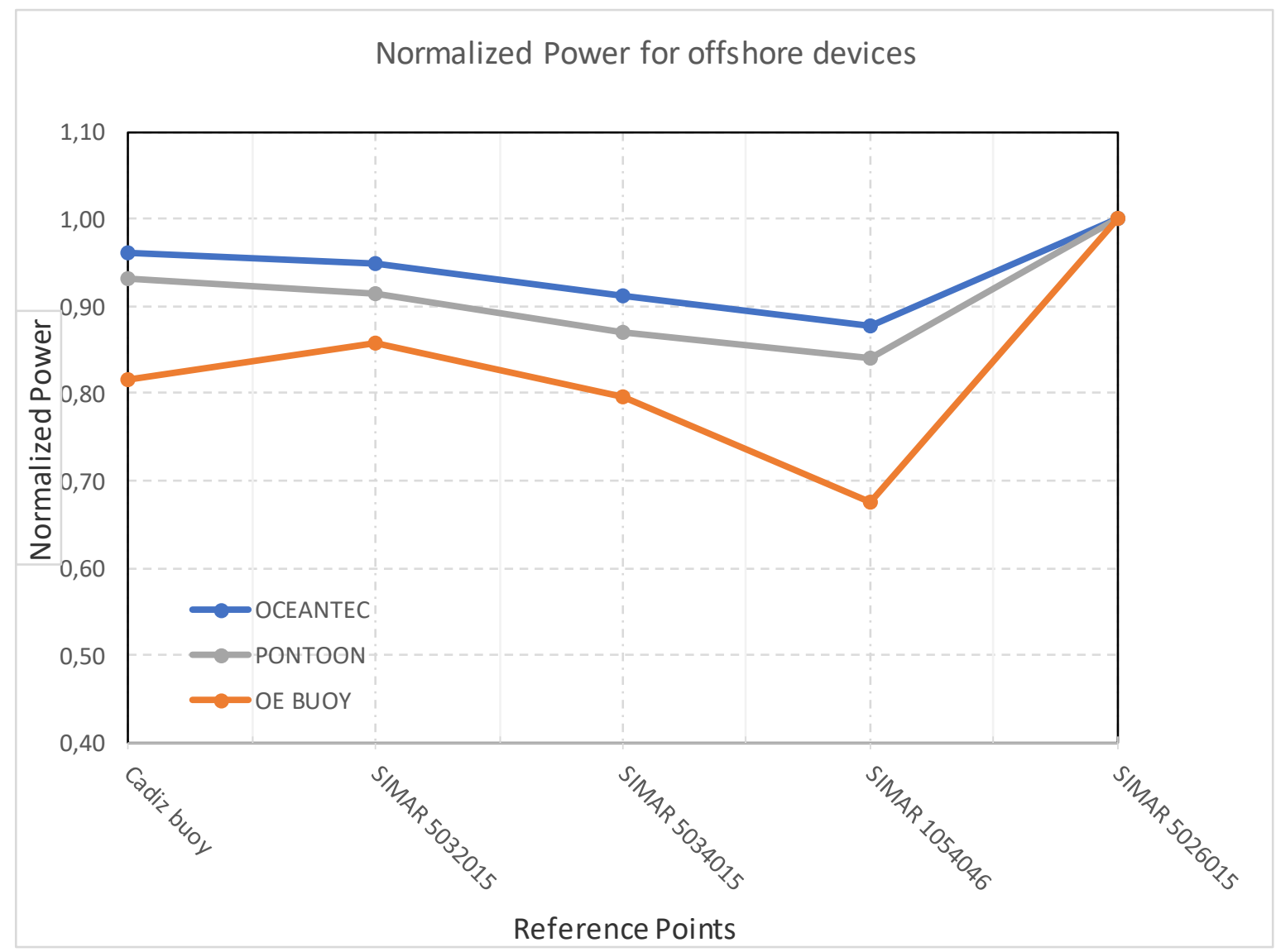

Fig. 8 Normalized electric power for the offshore devices, Oceantec, Pontoon and OE Buoy in the reference points.

For Oceantec, Pontoon and OE Buoy, the locations SIMAR 1054046 and SIMAR 5034015 appear to be the less energetic for the three ones, however OE Buoy shows a steeper low. The location SIMAR 5026015 is the most energetic (figure 8). 


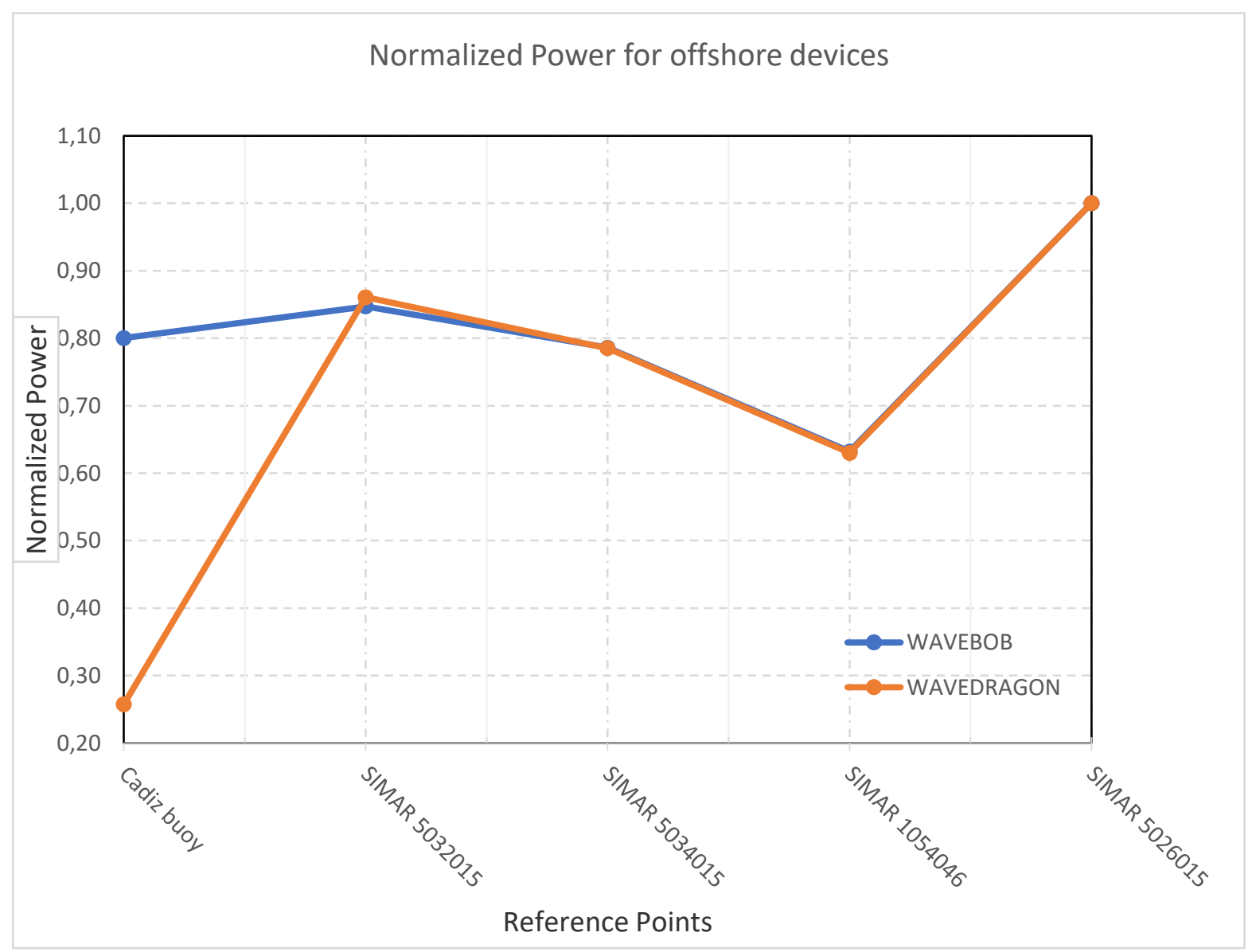

Fig. 9 Normalized electric power for the offshore devices, Wavebob and Wave Dragon in the reference points.

Wave Dragon presents a quite low energy value in the location Cádiz buoy, there is another low energy value in the location SIMAR 1054046. The most energetic location appears to be the location SIMAR 5026015. For Wavebob the less energetic location seems to be the location SIMAR 1054046 and the most energetic location, the SIMAR 5026015 (figure 9). 


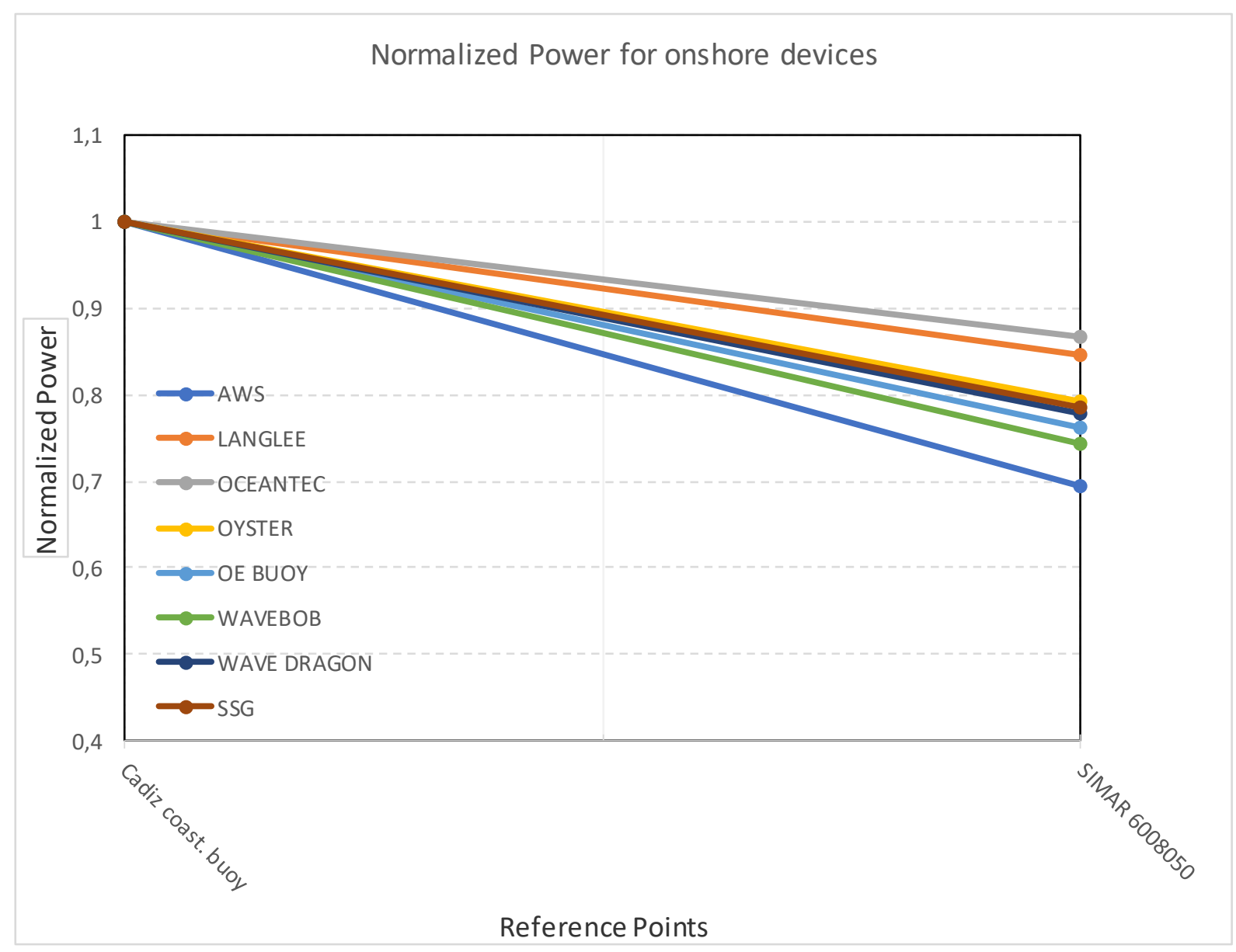

Fig. 10 Normalized electric power for the onhore devices, AWS, Langlee, Oceantec, Oyster, OE Buoy, Wavebob, Wave Dragon and SSG in the reference points.

For all the onshore devices studied, the location SIMAR 6008050 appear to be the less energetic while the location Cádiz coastal buoy is the most energetic (figure 10).

\section{Discussion}

Following the obtained in this work, in the offshore reference locations (table 3 ) at the Bay of Cádiz, the range of average electric power in $\mathrm{kW}$ for the different WECs is Pelamis [61 84] kW, Aqua Buoy [18 38] kW, AWS [111 172] kW, Oceantec [101 115] kW, Pontoon [183 217] kW, Wavebob [62 98] kW, Wave Dragon [342 1329] kW. In the onshore reference locations (table 4) at the Bay of Cádiz, the range of average electric power in $\mathrm{kW}$ for the different WECs is AWS [59 85] kW, Langlee [41 49] kW, Oyster [45 57] kW, OE Buoy [54 $71] \mathrm{kW}$, Wavebob [39 53] kW, Wave Dragon [526 676] kW, SSG [821 1046] kW.

In the paper of Gonçalves et al. [8], the average electric power in different locations around the Canary Islands is obtained. The range of average electric power in $\mathrm{kW}$ for the different WECs is Aqua Buoy [11 27] kW, Wave Dragon [365 479] kW, Pelamis [46 88] kW. Comparing the maximum electric power of each offshore WECs at the bay of Cádiz and Canary Islands, it can be seen that Aqua Buoy's average electric power is $40.7 \%$ higher in the bay of Cádiz than in the Canary Islands. Wave Dragon's average electric power is $177.45 \%$ higher in the bay of Cádiz than in the Canary Islands. On the other hand, Pelamis average electric power is $4.76 \%$ higher in the Canary Islands than in the bay of Cádiz. 
In the work of Diaconu and Rusu [31], the performance provided by various technologies for wave energy conversion that would operate on the western side of the Black Sea is presented. The average electric power in $\mathrm{kW}$ for the WECs is Wave Dragon $392 \mathrm{~kW}$, Pelamis $60 \mathrm{~kW}$, Aqua Buoy $16 \mathrm{~kW}$, AWS $60 \mathrm{~kW}$, Oceantec $96 \mathrm{~kW}$, Pontoon $164 \mathrm{~kW}$, Wavebob $55 \mathrm{~kW}$. Making a comparison of the maximum electric power of each offshore WECs at the bay of Cádiz and the western side of Black Sea, for all the WECs considered, the bay of Cádiz obtained higher values of electric power than the Black Sea. Being the average electric power of Wave Dragon is $239 \%$ higher in the bay of Cádiz, Pelamis $40 \%$, Aqua Buoy 137.5\%, AWS $186.67 \%$, Oceantec $19.79 \%$, Pontoon $32.31 \%$ and Wavebob $78.18 \%$.

In the paper of Silva et al. [17], the output of five different technologies for the conversion of wave energy is assessed in some relevant locations from the Portuguese nearshore. The range of average electric power in $\mathrm{kW}$ for the different offshore WECs, in those locations, is Aqua Buoy [30 36] kW and Pelamis [86 102] kW. The range of average electric power in $\mathrm{kW}$ for the different onshore WECs, in those locations, is Oyster [71 107] $\mathrm{kW}$, Wave Dragon [599 905] kW, and SSG [2040 3025] kW. Comparing the maximum electric power of each offshore WECs at the bay of Cádiz and the Portuguese continental coast, for Aqua Buoy is 5.5\% higher at the bay of Cádiz than at the Portuguese coast, for Pelamis is $21.43 \%$ higher in the Portuguese coast than at the bay of Cádiz. Making a comparison of the maximum electric power of each onshore WECs at the bay of Cádiz and Portuguese continental coast, the Portuguese continental coast presents higher values of electric power than the bay of Cádiz. Being the average electric power of Wave Dragon is $33.88 \%$ higher on the Portuguese coast, of Oyster $87.72 \%$, and of SSG $189.2 \%$.

In the work of Rusu [39], the performances of three WEC types in three different groups of coastal environments: the western Iberian nearshore, islands, and an enclosed environment is studied. Regarding northwestern Spain, the range of average electric power in $\mathrm{kW}$ for the different offshore WECs is Oceantec [94 107] kW, Pelamis [114 127] kW, Pontoon [220 239] $\mathrm{kW}$, Wave Dragon [2037 2198] kW. Comparing the maximum electric power of each offshore WECs at the bay of Cádiz and in the northwestern of Spain, for Oceantec is $7.48 \%$ higher at the bay of Cádiz than in the northwestern of Spain, for Pelamis, Pontoon and Wave Dragon is higher in the northwestern of Spain than at the bay of Cádiz, being $51.2 \%, 10.14 \%$, and $65.39 \%$ respectively. With regard to the Portuguese coast, the range of average electric power in $\mathrm{kW}$ for the different offshore WECs is Pelamis [79 102] kW, AWS [247 296] kW, Aqua Buoy [29 36] kW, Wave Dragon [1153 1475] kW. Making a comparison of the maximum electric power of each offshore WECs at the bay of Cádiz and in the Portuguese coast, for Aqua Buoy is 5.55\% higher at the bay of Cádiz than in the Portuguese coast, for Pelamis, AWS and Wave Dragon is higher in the Portuguese coast than at the bay of Cádiz, being $21.43 \%, 72.09 \%$, and $10.98 \%$ respectively. With respect to the Canary Islands, the range of average electric power in $\mathrm{kW}$ for the different offshore WECs is Pelamis [65 90] kW, AWS [255 277] kW, Aqua Buoy [24 32] kW, Wavebob [87 106] kW. Comparing the maximum electric power of each offshore WECs at the bay of Cádiz and in the Canary Islands, for Aqua Buoy is $18.75 \%$ higher at the bay of Cádiz than in the Canary Islands, for Pelamis, AWS, and Wavebob is higher in the Canary Islands than at the bay of Cádiz, being $7.14 \%, 61.04 \%$, and $8.16 \%$ respectively. Regarding the Black Sea, the range of average electric power in $\mathrm{kW}$ for the different offshore WECs is Pelamis $60 \mathrm{~kW}$, Aqua Buoy $16 \mathrm{~kW}$, and Wave Dragon $391 \mathrm{~kW}$. Making a comparison of the maximum electric power of each offshore WECs at the bay of Cádiz and the western side of Black Sea, for all the WECs considered, the bay of Cádiz obtained higher values of electric power than the Black Sea. Being the average electric power of Pelamis is $40 \%$ higher in the bay of Cádiz, Aqua Buoy is 137.5\%, Wave Dragon 239.90\%. With regards to the North Sea at Fino station, the range of 
average electric power in $\mathrm{kW}$ for the different offshore WECs is Pelamis $70 \mathrm{~kW}$, Aqua Buoy $12 \mathrm{~kW}$, and Wave Dragon $735 \mathrm{~kW}$. Comparing the maximum electric power of each offshore WECs at the bay of Cádiz and the North Sea at Fino station, for all the WECs considered, the bay of Cádiz obtained higher values of electric power than the North Sea at Fino station. Being the average electric power of Pelamis is $20 \%$ higher in the bay of Cádiz, Aqua Buoy $216.67 \%$ and Wave Dragon $80.82 \%$.

In the paper of Vannucchi and Cappietti [40], the performances of different WECs have been evaluated in the Italian coastal areas, the coast of Tuscany, Liguria, Sardinia, and Sicily. Regarding Italian coastal areas, the range of average electric power in $\mathrm{kW}$ for the different offshore WECs is Aqua Buoy [3 21] kW, Pelamis [7 49] kW, AWS [7 99] kW, and Wave Dragon [227 540.4] kW and for the onshore WEC Oyster [8 48] kW. Making a comparison of the maximum electric power of each offshore WECs at the bay of Cádiz and in the Italian coastal areas, for all the WECs considered, the bay of Cádiz obtained higher values of electric power than Italian coastal areas. Being the average electric power of Aqua Buoy is $80.95 \%$ higher in the bay of Cádiz, Pelamis 71.43\%, AWS 73.73\%, Wave Dragon $145.93 \%$, and Oyster $18.75 \%$.

In the work of Rusu and Guedes [41], three WECs performance around Madeira Islands is presented. With regard to Madeira Islands, the range of average electric power in $\mathrm{kW}$ for the different offshore WECs is Pelamis [105 135] kW, Wave Dragon [1147 1644] kW, and Aqua Buoy [40 50] kW. Comparing the maximum electric power of each offshore WECs at the bay of Cádiz and Madeira Islands, for all the WECs considered, Madeira Islands obtained higher values of electric power. Being the average electric power of Pelamis is $60.71 \%$ higher in the Madeira Islands, Aqua Buoy is $31.58 \%$, and Wave Dragon is $23.70 \%$.

In the paper of Bozzi and at al. [42], the performance of three waves energy converters is estimated for two of the most energetic Italian locations. The sites are Alghero, on the western coast of Sardinia, and Mazara del Vallo, on the Sicily Strait. The average electric power in $\mathrm{kW}$ for the WECs is Aqua Buoy [9 22] kW, Pelamis [32 71] kW, and Wave Dragon [270 616] kW. Making a comparison of the maximum electric power of each offshore WECs at the bay of Cádiz and in the Italian locations, for all the WECs considered, the bay of Cádiz obtained higher values of electric power than Italian locations. Being the average electric power of Aqua Buoy is $72.73 \%$ higher in the bay of Cádiz, Pelamis $18.31 \%$ and Wave Dragon $115.75 \%$.

In order to analyze the variability of the energy capture in the studied area of the bay of Cádiz, a comparison of the power obtained by each WECs in the different points of reference is carried out.

Focusing on offshore devices, table 3, for Pelamis, the maximum difference in power is obtained between SIMAR 5026015 and SIMAR 105406 points, being 37.35\%. And the minimum difference is obtained between SIMAR 5032015 and Cádiz buoy points, being of $0.8 \%$. The difference between the other reference points is among these quantities. For Aqua Buoy, the maximum power difference is given between SIMAR 5032015 and SIMAR 1054046 points, being $114.124 \%$. And the minimum difference is obtained between Cádiz buoy and SIMAR 5032015 points, being of $0.45 \%$. The difference between the other reference points is among these quantities. For AWS, the maximum power difference is given between SIMAR 5026015 and SIMAR 1054046 points, being 55.38\%. And the minimum difference is obtained between Cádiz buoy and SIMAR 5032015 points, being of $3.36 \%$. The difference between the other reference points is among these quantities. For Langlee, the maximum power difference is given between SIMAR 5026015 and SIMAR 1054046 points, being $15.69 \%$. And the minimum difference is obtained between the Cádiz buoy and SIMAR 5032015 points, being $1.38 \%$. The difference between the other reference points is among 
these quantities. For Oceantec, the maximum power difference is given between SIMAR 5026015 and SIMAR 1054046 points, being 13.95\%. And the minimum difference is obtained between Cádiz buoy and SIMAR 5032015 points, being 1.37\%. The difference between the other reference points is among these quantities. For Pontoon, the maximum power difference is given between SIMAR 5026015 and SIMAR 1054046 points, being 18.78\%. And the minimum difference is obtained between Cádiz buoy and SIMAR 5032015 points, being $1.91 \%$. The difference between the other reference points is among these quantities. For OE Buoy, the maximum power difference is given between SIMAR 5026015 and SIMAR 1054046 points, being $48.31 \%$. And the minimum difference is obtained between Cádiz buoy and SIMAR 5032015 points, being 5.02\%. The difference between the other reference points is among these quantities. For Wavebob, the maximum power difference is given between SIMAR 5026015 and SIMAR 1054046 points, being 58.23\%. And the minimum difference is obtained between Cádiz buoy and SIMAR 5032015 points, being $1.82 \%$. The difference between the other reference points is among these quantities. For Wave Dragon, the maximum power difference is given between SIMAR 5026015 and Cádiz buoy points, being $288.40 \%$. And the minimum difference is obtained between SIMAR 5034015 and SIMAR 5032015 points, being $9.58 \%$. The difference between the other reference points is among these quantities.

Regarding onshore devices, the power difference between the two studied points, Cádiz coastal buoy and SIMAR 6008050 points is: for AWS of $44.01 \%$, for Langlee of $18.35 \%$, for Oceantec of $15.38 \%$, for Oyster of $26.15 \%$, for OE Buoy of $31.31 \%$, for Wavebob of $34.44 \%$, for Wave Dragon of $28.62 \%$ and for SSG of $27.44 \%$.

With regard to the paper of Gonçalves et al. [8], the maximum power difference at the different locations studied around Canary Island is: for Aqua Buoy of $145.45 \%$, for Wave Dragon of $31.23 \%$ and for Pelamis of $91.30 \%$. With respect to the paper of Silva et alt. (Dina), the maximum power difference at the different locations studied in the Portuguese nearshore is: for Aqua Buoy of 20\%, for Pelamis of $18.60 \%$, for Oyster of $50.70 \%$, for Wave Dragon of $51.09 \%$ and for SSG of $48.28 \%$. Regarding the work of Rusu [39], the maximum power difference at the different locations studied in the northwestern of Spain is: for Oceantec $13.83 \%$, for Pelamis $11,40 \%$, for Potoon $8.64 \%$, and for Wave Dragon $7.90 \%$. The maximum power difference at the different locations studied on the Portuguese coast is: for Pelamis $29.11 \%$, for AWS $19.84 \%$, for Aqua Buoy $24.14 \%$, for Wave Dragon $27.93 \%$. The maximum power difference at the different locations studied in the Canary Islands is: for Pelamis $38.46 \%$, for AWS $8.63 \%$, for Aqua Buoy 33.33\%, for Wavebob 21.84\%. With regard to the paper of Vannucchi and Cappietti [40], the maximum power difference at the different locations studied in Italian coastal areas is: for Aqua Buoy $600 \%$, for Pelamis $600 \%$, for AWS $1314.29 \%$, for Wave Dragon $138.06 \%$, and for Oyster 500\%. With respect to the work of Rusu and Guedes [41], the maximum power difference at the different locations studied around Madeira Islands is: for Aqua Buoy 25\%, for Pelamis 28.57\%, and for Wave Dragon 43.33\%. Regarding the paper of Bozzi and at al. [42], the maximum power difference at the different locations studied in Italy: for Aqua Buoy $144.44 \%$, for Pelamis $121.88 \%$, and for Wave Dragon 128.15\%.

Making a comparison between the bay of Cádiz and the different locations studied in the before cited papers, it can be observed that the variability of power obtained in the bay of Cádiz is similar to the variation obtained by them. Moreover, it is much less than in the coastal Italian locations studied in the work of Vannucchi and Cappietti [40]. 


\section{Conclusions}

A medium-term evaluation of the wave conditions (corresponding to the time interval 2010-2014) was presented in the present work considering several reference locations in the bay of Cádiz. This was made using the data available from the Spanish Agency Puertos del Estado.

On this basis, the efficiency of nine energy converters, covering the full scale from the point of view of their location (offshore and onshore), was evaluated in the bay of Cádiz. The estimations were made by diagrams for the bivariate distributions of the occurrences corresponding to the sea states defined by significant wave height and energy period.

A good agreement between the characteristics of the power matrices of the wave energy converters operating in a certain place and the diagrams for the bivariate distributions of the sea states occurrences corresponding to the considered location represent a key issue in selecting the most appropriate location for a WEC. An example is given by the reference location Cádiz coastal buoy, onshore point, in which Wave Dragon would produce more energy $(676.4 \mathrm{~kW})$ than in the offshore location Cádiz buoy $(342.1 \mathrm{~kW})$.

Following the results presents in this work, the bay of Cádiz has obtained higher electric power than the Canary Islands for Aqua Buoy and Wave Dragon, and higher than the northwester of Spain for Oceantec. Moreover, the bay of Cádiz has presented higher values of electric power than the western side of the Black Sea and the North Sea at Fino station for all the WECs studied. What is more, the bay of Cádiz has reached higher values of electric power than the locations studied around Italy for all WECs studied. The variability of power obtained in the bay of Cádiz is similar to the variation obtained in other locations studied (the Canary Islands, Portuguese nearshore, Madeira Islands, northwestern of Spain). Moreover, it is much less than in the areas of Italy. Taking into consideration this study, it can be said that the bay of Cádiz is a suitable place for wave energy extraction.

It is necessary to consider that the non-technical factors should also be considered to reach the final decisions about the proper location and type of WECs to install. Furthermore, the concepts used are ones that have information available in the literature, which is useful to provide a general order of magnitude of the expected contribution. However, some of them are not commercially available for deployment, so a more detailed study will be required after the first level of decisions are made.

Thinking in future studies, the first thing to do would be to consult the commercial availability of the WECs. In the second place, studying the possibility of establishing a WEC farm in the bay of Cádiz, taking into account the use of maritime space by other activities and the design of the possible WECs farm. Next studies would be some techno-economic analysis to cost the WEC energy converted, some analysis of the correlation between converted wave power and electricity demand, the possibility of optimization of the WEC for the chosen locations, and so on.

Funding: This research is funding by Proyecto PID2019-108336GB-I00 financiado por MCIN/AEI/10.13039/501100011033"

Acknowledgments: Programa de Fomento e Impulso de la Investigación y la Transferencia en la Universidad de Cadiz (UCA) 2018/19 and 2019/20. This research is a result of the research stay of the first author to CENTEC, Instituto Superior Tecnico (IST), Universidade de Lisboa, Portugal. The authors would like to thank the anonymous reviewers who have contributed to improving this paper. 


\section{Appendix A} shown.

In this appendix, the power matrix of the different WECs system used in this research is

Table A1. Power matrix (in kW) for the wave energy converter Wave Dragon [31]

\begin{tabular}{|c|c|c|c|c|c|c|c|c|c|c|c|c|c|}
\hline \multicolumn{10}{|c|}{ Power matrix (in kW) } \\
\hline \multirow{2}{*}{$\begin{array}{l}\text { Hs } \\
(\mathrm{m})\end{array}$} & $\mathbf{5}$ & $\mathbf{6}$ & $\mathbf{7}$ & $\mathbf{8}$ & $\mathbf{9}$ & $\mathbf{1 0}$ & $\mathbf{1 1}$ & $\mathbf{1 2}$ & $\mathbf{1 3}$ & $\mathbf{1 4}$ & $\mathbf{1 5}$ & $\mathbf{1 6}$ & $\mathbf{1 8}$ \\
\hline $\mathbf{1}$ & 160 & 250 & 360 & 360 & 360 & 360 & 360 & 360 & 320 & 280 & 250 & 220 & 180 \\
\hline $\mathbf{2}$ & 640 & 700 & 840 & 900 & 1190 & 1190 & 1190 & 1190 & 1070 & 950 & 830 & 710 & 590 \\
\hline $\mathbf{3}$ & 0 & 1450 & 1610 & 1750 & 2000 & 2620 & 2620 & 2620 & 2360 & 2100 & 1840 & 1570 & 1310 \\
\hline $\mathbf{4}$ & 0 & 0 & 2840 & 3220 & 3710 & 4200 & 5320 & 5320 & 4430 & 3930 & 3440 & 2950 & 2460 \\
\hline $\mathbf{5}$ & 0 & 0 & 0 & 4610 & 5320 & 6020 & 7000 & 7000 & 6790 & 6090 & 5250 & 3950 & 3300 \\
\hline $\mathbf{6}$ & 0 & 0 & 0 & 0 & 6720 & 7000 & 7000 & 7000 & 7000 & 7000 & 6860 & 5110 & 4200 \\
\hline $\mathbf{7}$ & 0 & 0 & 0 & 0 & 0 & 7000 & 7000 & 7000 & 7000 & 7000 & 7000 & 6650 & 5740 \\
\hline
\end{tabular}

Table A2. Power matrix (in $\mathrm{kW}$ ) for the wave energy converter Archimedes Wave Swing [31]

\begin{tabular}{|c|c|c|c|c|c|c|c|c|c|c|c|c|c|c|c|c|c|c|c|c|}
\hline \multicolumn{21}{|c|}{ Power matrix (in kW) } \\
\hline \multirow[b]{2}{*}{$\begin{array}{l}\mathrm{Hs} \\
(\mathrm{m})\end{array}$} & \multicolumn{20}{|c|}{$\mathrm{Tp}(\mathrm{s})$} \\
\hline & 5 & 5.5 & 6 & 6.5 & 7 & 7.5 & 8 & 8.5 & 9 & 9.5 & 10 & 10.5 & 11 & 11.5 & 12 & 12.5 & 13 & 13.5 & 14 & 14.5 \\
\hline 1 & 2 & 7 & 13 & 19 & 26 & 34 & 41 & 48 & 58 & 68 & 81 & 93 & 105 & 118 & 131 & 144 & 153 & 163 & 183 & 203 \\
\hline 1.5 & 4 & 15 & 28 & 41 & 56 & 72 & 85 & 99 & 121 & 143 & 173 & 203 & 226 & 248 & 266 & 285 & 309 & 334 & 357 & 380 \\
\hline 2 & 8 & 26 & 49 & 73 & 100 & 127 & 150 & 172 & 210 & 247 & 292 & 337 & 366 & 395 & 418 & 442 & 482 & 523 & 543 & 563 \\
\hline 2.5 & 15 & 43 & 78 & 113 & 159 & 205 & 234 & 263 & 320 & 376 & 438 & 499 & 531 & 563 & 603 & 643 & 675 & 708 & 741 & 774 \\
\hline 3 & 25 & 61 & 111 & 161 & 227 & 293 & 339 & 386 & 453 & 521 & 600 & 680 & 722 & 765 & 827 & 888 & 897 & 906 & 945 & 984 \\
\hline 3.5 & 35 & 92 & 155 & 218 & 305 & 391 & 454 & 517 & 605 & 694 & 772 & 851 & 913 & 975 & 1036 & 1096 & 1119 & 1141 & 1163 & 1185 \\
\hline 4 & 35 & 114 & 194 & 273 & 380 & 486 & 572 & 659 & 776 & 894 & 961 & 1027 & 1103 & 1179 & 1227 & 1275 & 1316 & 1357 & 1365 & 1374 \\
\hline 4.5 & 0 & 0 & 235 & 332 & 479 & 626 & 722 & 819 & 957 & 1096 & 1168 & 1240 & 1320 & 1401 & 1449 & 1497 & 1547 & 1598 & 1590 & 1583 \\
\hline 5 & 0 & 0 & 280 & 400 & 592 & 784 & 899 & 1014 & 1144 & 1274 & 1380 & 1487 & 1569 & 1651 & 1691 & 1731 & 1785 & 1838 & 1807 & 1777 \\
\hline 5.5 & 0 & 0 & 320 & 432 & 641 & 849 & 1033 & 1216 & 1331 & 1446 & 1568 & 1690 & 1778 & 1867 & 1919 & 1970 & 1977 & 1984 & 1994 & 2005 \\
\hline 6 & 0 & 0 & 0 & 0 & 680 & 944 & 1155 & 1367 & 1495 & 1623 & 1759 & 1895 & 1963 & 2072 & 2137 & 2202 & 2205 & 2207 & 2226 & 2246 \\
\hline 6.5 & 0 & 0 & 0 & 0 & 720 & 1123 & 1335 & 1547 & 1678 & 1809 & 1963 & 2116 & 2200 & 2284 & 2332 & 2380 & 2425 & 2470 & 2452 & 2434 \\
\hline
\end{tabular}

Table A3. Power matrix (in kW) for the wave energy converter Langlee [31]

\begin{tabular}{|c|c|c|c|c|c|c|c|c|c|c|c|c|c|}
\hline \multicolumn{10}{|c|}{ Power matrix (in kW) } \\
\hline \multirow{3}{*}{$\mathrm{Hs}(\mathrm{m})$} & $\mathbf{4}$ & $\mathbf{5}$ & $\mathbf{6}$ & $\mathbf{7}$ & $\mathbf{8}$ & $\mathbf{9}$ & $\mathbf{1 0}$ & $\mathbf{1 1}$ & $\mathbf{1 2}$ & $\mathbf{1 3}$ & $\mathbf{1 4}$ & $\mathbf{1 5}$ & $\mathbf{1 6}$ \\
\hline $\mathbf{1}$ & 19 & 29 & 47 & 57 & 52 & 37 & 29 & 20 & 17 & 13 & 9 & 7 & 7 \\
\hline $\mathbf{1 . 5}$ & 42 & 63 & 92 & 111 & 109 & 65 & 56 & 38 & 29 & 22 & 19 & 13 & 11 \\
\hline $\mathbf{2}$ & 66 & 99 & 151 & 201 & 165 & 105 & 85 & 59 & 52 & 41 & 23 & 24 & 19 \\
\hline $\mathbf{2 . 5}$ & 0 & 160 & 242 & 262 & 226 & 166 & 118 & 83 & 70 & 57 & 39 & 29 & 26 \\
\hline $\mathbf{3}$ & 0 & 213 & 319 & 372 & 327 & 211 & 152 & 116 & 94 & 75 & 66 & 45 & 42 \\
\hline $\mathbf{3 . 5}$ & 0 & 0 & 436 & 503 & 408 & 293 & 203 & 148 & 115 & 93 & 75 & 58 & 44 \\
\hline $\mathbf{4}$ & 0 & 0 & 554 & 540 & 521 & 355 & 261 & 192 & 144 & 123 & 84 & 81 & 56 \\
\hline $\mathbf{4 . 5}$ & 0 & 0 & 645 & 746 & 587 & 379 & 302 & 236 & 190 & 154 & 106 & 90 & 74 \\
\hline $\mathbf{5}$ & 0 & 0 & 796 & 926 & 695 & 486 & 341 & 287 & 211 & 168 & 136 & 111 & 94 \\
\hline $\mathbf{5 . 5}$ & 0 & 0 & 0 & 955 & 808 & 603 & 430 & 343 & 231 & 201 & 150 & 120 & 97 \\
\hline $\mathbf{6}$ & 0 & 0 & 0 & 1161 & 957 & 642 & 481 & 329 & 289 & 212 & 172 & 145 & 111 \\
\hline $\mathbf{6 . 5}$ & 0 & 0 & 0 & 1476 & 1039 & 702 & 488 & 397 & 312 & 237 & 204 & 153 & 120 \\
\hline $\mathbf{7}$ & 0 & 0 & 0 & 1665 & 1197 & $82 \pi 9$ & 612 & 466 & 385 & 252 & 223 & 181 & 146 \\
\hline
\end{tabular}


Table A4. Power matrix (in kW) for the wave energy converter Oceantec [31]

\begin{tabular}{|c|c|c|c|c|c|c|c|c|c|c|c|c|c|}
\hline \multicolumn{110}{|c|}{ Power matrix (in kW) } \\
\hline \multirow{3}{*}{ Hs(m) } & $\mathbf{6}$ & $\mathbf{7}$ & $\mathbf{8}$ & $\mathbf{9}$ & $\mathbf{1 0}$ & $\mathbf{1 1}$ & $\mathbf{1 2}$ & $\mathbf{1 3}$ & $\mathbf{1 4}$ & $\mathbf{1 5}$ & $\mathbf{1 6}$ & $\mathbf{1 7}$ & $\mathbf{1 8}$ \\
\hline & $\mathbf{6}$ & 85 & 59 & 39 & 25 & 16 & 10 & 7 & 5 & 3 & 2 & 2 & 1 \\
\hline $\mathbf{1}$ & 191 & 196 & 133 & 89 & 57 & 36 & 23 & 15 & 10 & 7 & 5 & 3 & 3 \\
\hline $\mathbf{1 . 5}$ & 339 & 348 & 234 & 158 & 101 & 64 & 41 & 27 & 18 & 12 & 9 & 6 & 4 \\
\hline $\mathbf{2}$ & 500 & 500 & 364 & 245 & 158 & 101 & 65 & 42 & 28 & 19 & 13 & 10 & 7 \\
\hline $\mathbf{3}$ & 500 & 500 & 500 & 337 & 228 & 145 & 93 & 61 & 41 & 28 & 19 & 14 & 10 \\
\hline $\mathbf{3 . 5}$ & 500 & 500 & 500 & 420 & 309 & 196 & 127 & 83 & 55 & 38 & 26 & 19 & 13 \\
\hline $\mathbf{4}$ & 500 & 500 & 500 & 500 & 401 & 258 & 166 & 109 & 72 & 49 & 34 & 24 & 18 \\
\hline $\mathbf{4 . 5}$ & 500 & 500 & 500 & 500 & 500 & 326 & 210 & 138 & 92 & 62 & 43 & 31 & 22 \\
\hline $\mathbf{5}$ & 500 & 500 & 500 & 500 & 500 & 383 & 259 & 170 & 113 & 77 & 54 & 38 & 27 \\
\hline $\mathbf{5 . 5}$ & 500 & 500 & 500 & 500 & 500 & 389 & 308 & 205 & 137 & 93 & 65 & 46 & 33 \\
\hline
\end{tabular}

Table A5. Power matrix (in kW) for the wave energy converter Pelamis [31]

\begin{tabular}{|c|c|c|c|c|c|c|c|c|c|c|c|c|}
\hline \multicolumn{13}{|c|}{ Power matrix (in kW) } \\
\hline \multirow[t]{2}{*}{$\mathrm{Hs}(\mathrm{m})$} & \multicolumn{12}{|c|}{$\mathrm{Te}(\mathrm{s})$} \\
\hline & 5 & 5.5 & 6 & 6.5 & 7 & 7.5 & 8 & 9 & 10 & 11 & 12 & 13 \\
\hline 0.5 & 0 & 0 & 0 & 0 & 0 & 0 & 0 & 0 & 0 & 0 & 0 & 0 \\
\hline 1 & 0 & 22 & 29 & 34 & 37 & 38 & 38 & 35 & 29 & 23 & 0 & 0 \\
\hline 1.5 & 32 & 50 & 65 & 76 & 83 & 86 & 86 & 78 & 65 & 53 & 42 & 33 \\
\hline 2 & 57 & 88 & 115 & 136 & 148 & 153 & 152 & 138 & 116 & 93 & 74 & 59 \\
\hline 2.5 & 89 & 138 & 180 & 212 & 231 & 238 & 238 & 216 & 181 & 146 & 116 & 92 \\
\hline 3 & 129 & 198 & 260 & 305 & 332 & 340 & 332 & 292 & 240 & 210 & 167 & 132 \\
\hline 3.5 & 0 & 270 & 354 & 415 & 438 & 440 & 424 & 377 & 326 & 260 & 215 & 180 \\
\hline 4 & 0 & 0 & 462 & 502 & 540 & 546 & 530 & 475 & 384 & 339 & 267 & 213 \\
\hline 4.5 & 0 & 0 & 544 & 635 & 642 & 648 & 628 & 562 & 473 & 382 & 338 & 266 \\
\hline 5 & 0 & 0 & 0 & 739 & 726 & 731 & 707 & 670 & 557 & 472 & 369 & 328 \\
\hline 5.5 & 0 & 0 & 0 & 750 & 750 & 750 & 750 & 737 & 658 & 530 & 446 & 355 \\
\hline 6 & 0 & 0 & 0 & 0 & 750 & 750 & 750 & 750 & 711 & 619 & 512 & 415 \\
\hline 6.5 & 0 & 0 & 0 & 0 & 750 & 750 & 750 & 750 & 750 & 658 & 579 & 481 \\
\hline 7 & 0 & 0 & 0 & 0 & 0 & 750 & 750 & 750 & 750 & 750 & 613 & 525 \\
\hline 7.5 & 0 & 0 & 0 & 0 & 0 & 0 & 750 & 750 & 750 & 750 & 686 & 593 \\
\hline 8 & 0 & 0 & 0 & 0 & 0 & 0 & 0 & 750 & 750 & 750 & 750 & 625 \\
\hline
\end{tabular}


Table A6. Power matrix (in $\mathrm{kW}$ ) for the wave energy converter Pontoon [31]

\begin{tabular}{|c|c|c|c|c|c|c|c|c|c|c|c|c|c|}
\hline \multicolumn{110}{|c|}{ Power matrix (in kW) } \\
\hline \multirow{2}{*}{$\mathrm{Hs}(\mathrm{m})$} & $\mathbf{4}$ & $\mathbf{5}$ & $\mathbf{6}$ & $\mathbf{7}$ & $\mathbf{8}$ & $\mathbf{9}$ & $\mathbf{1 0})$ & $\mathbf{1 1}$ & $\mathbf{1 2}$ & $\mathbf{1 3}$ & $\mathbf{1 4}$ & $\mathbf{1 5}$ & $\mathbf{1 6}$ \\
\hline $\mathbf{1}$ & 180 & 166 & 153 & 171 & 125 & 87 & 72 & 65 & 85 & 85 & 37 & 29 & 16 \\
\hline $\mathbf{1 . 5}$ & 223 & 195 & 157 & 148 & 261 & 192 & 223 & 139 & 155 & 155 & 74 & 67 & 46 \\
\hline $\mathbf{2}$ & 0 & 0 & 214 & 227 & 396 & 335 & 237 & 235 & 172 & 138 & 115 & 104 & 70 \\
\hline $\mathbf{2 . 5}$ & 0 & 0 & 0 & 440 & 598 & 514 & 379 & 342 & 204 & 169 & 142 & 128 & 95 \\
\hline $\mathbf{3}$ & 0 & 0 & 0 & 681 & 801 & 735 & 594 & 486 & 199 & 174 & 151 & 134 & 121 \\
\hline $\mathbf{3 . 5}$ & 0 & 0 & 0 & 904 & 1035 & 949 & 788 & 617 & 239 & 209 & 183 & 164 & 146 \\
\hline $\mathbf{4}$ & 0 & 0 & 0 & 1131 & 1269 & 1163 & 982 & 743 & 285 & 248 & 216 & 195 & 175 \\
\hline $\mathbf{4 . 5}$ & 0 & 0 & 0 & 1358 & 1488 & 1374 & 1187 & 869 & 330 & 287 & 250 & 225 & 201 \\
\hline $\mathbf{5}$ & 0 & 0 & 0 & 1585 & 1712 & 1585 & 1392 & 988 & 380 & 334 & 285 & 263 & 226 \\
\hline $\mathbf{5 . 5}$ & 0 & 0 & 0 & 1812 & 1937 & 1798 & 2138 & 1107 & 429 & 381 & 323 & 301 & 261 \\
\hline $\mathbf{6}$ & 0 & 0 & 0 & 2040 & 2162 & 2010 & 2884 & 1234 & 439 & 416 & 361 & 336 & 295 \\
\hline $\mathbf{6 . 5}$ & 0 & 0 & 0 & 2267 & 2386 & 2221 & 3143 & 1360 & 449 & 450 & 406 & 372 & 329 \\
\hline $\mathbf{7}$ & 0 & 0 & 0 & 2494 & 2611 & 2433 & 3619 & 1483 & 506 & 464 & 451 & 408 & 363 \\
\hline
\end{tabular}

Table A7. Power matrix (in kW) for the wave energy converter OE buoy [31]

\begin{tabular}{|c|c|c|c|c|c|c|c|c|c|c|c|c|c|}
\hline \multicolumn{10}{|c|}{ Power matrix (in kW) } \\
\hline \multirow{2}{*}{$\begin{array}{c}\text { Hs } \\
(\mathrm{m})\end{array}$} & $\mathbf{4}$ & $\mathbf{5}$ & $\mathbf{6}$ & $\mathbf{7}$ & $\mathbf{8}$ & $\mathbf{9}$ & $\mathbf{1 0}$ & $\mathbf{1 1}$ & $\mathbf{1 2}$ & $\mathbf{1 3}$ & $\mathbf{1 4}$ & $\mathbf{1 5}$ & $\mathbf{1 6}$ \\
\hline $\mathbf{1}$ & 8 & 17 & 27 & 42 & 56 & 59 & 52 & 44 & 40 & 38 & 40 & 38 & 30 \\
\hline $\mathbf{1 . 5}$ & 17 & 39 & 61 & 96 & 126 & 132 & 117 & 99 & 89 & 87 & 89 & 85 & 66 \\
\hline $\mathbf{2}$ & 30 & 69 & 108 & 170 & 224 & 235 & 208 & 177 & 159 & 154 & 159 & 151 & 118 \\
\hline $\mathbf{2 . 5}$ & 47 & 108 & 169 & 266 & 350 & 368 & 324 & 276 & 249 & 241 & 248 & 236 & 185 \\
\hline $\mathbf{3}$ & 68 & 155 & 244 & 383 & 504 & 530 & 467 & 398 & 358 & 347 & 357 & 340 & 266 \\
\hline $\mathbf{3 . 5}$ & 93 & 212 & 332 & 521 & 686 & 721 & 636 & 542 & 487 & 472 & 486 & 463 & 362 \\
\hline $\mathbf{4}$ & 121 & 276 & 433 & 680 & 896 & 942 & 831 & 708 & 636 & 616 & 634 & 605 & 473 \\
\hline $\mathbf{4 . 5}$ & 154 & 350 & 548 & 861 & 1130 & 1190 & 1050 & 896 & 805 & 780 & 803 & 765 & 599 \\
\hline $\mathbf{5}$ & 190 & 432 & 677 & 1060 & 1400 & 1470 & 1300 & 1110 & 994 & 963 & 991 & 945 & 739 \\
\hline $\mathbf{5 . 5}$ & 0 & 523 & 819 & 1290 & 1690 & 1780 & 1570 & 1340 & 1200 & 1170 & 1200 & 1140 & 894 \\
\hline $\mathbf{6}$ & 0 & 622 & 975 & 1530 & 2020 & 2120 & 1870 & 1590 & 1430 & 1390 & 1430 & 1360 & 1060 \\
\hline $\mathbf{6 . 5}$ & 0 & 730 & 1140 & 1800 & 2370 & 2490 & 2190 & 1870 & 1680 & 1630 & 1670 & 1600 & 1250 \\
\hline $\mathbf{7}$ & 0 & 847 & 1330 & 2080 & 2750 & 2880 & 2540 & 2170 & 1950 & 1890 & 1940 & 1850 & 1450 \\
\hline
\end{tabular}


Table A8. Power matrix (in kw) for the wave energy converter Wavebob [31

\begin{tabular}{|c|c|c|c|c|c|c|c|c|c|c|c|c|c|}
\hline \multicolumn{14}{|c|}{ Power matrix (in kW) } \\
\hline \multirow[b]{2}{*}{$\mathrm{Hs}(\mathrm{m})$} & \multicolumn{13}{|c|}{$\mathrm{Tp}(\mathrm{s})$} \\
\hline & 4 & 5 & 6 & 7 & 8 & 9 & 10 & 11 & 12 & 13 & 14 & 15 & 16 \\
\hline 1 & 6 & 11 & 19 & 25 & 30 & 44 & 50 & 53 & 44 & 34 & 22 & 20 & 17 \\
\hline 1.5 & 13 & 25 & 43 & 55 & 68 & 90 & 102 & 92 & 91 & 66 & 65 & 45 & 37 \\
\hline 2 & 24 & 45 & 65 & 100 & 121 & 153 & 175 & 151 & 122 & 126 & 87 & 61 & 58 \\
\hline 2.5 & 0 & 65 & 104 & 141 & 191 & 179 & 243 & 255 & 190 & 181 & 135 & 99 & 83 \\
\hline 3 & 0 & 96 & 137 & 205 & 244 & 357 & 293 & 353 & 260 & 248 & 184 & 137 & 120 \\
\hline 3.5 & 0 & 0 & 192 & 254 & 291 & 431 & 385 & 424 & 314 & 285 & 239 & 222 & 172 \\
\hline 4 & 0 & 0 & 256 & 366 & 403 & 551 & 536 & 531 & 473 & 420 & 289 & 268 & 179 \\
\hline 4.5 & 0 & 0 & 327 & 418 & 574 & 678 & 708 & 665 & 509 & 415 & 386 & 244 & 249 \\
\hline 5 & 0 & 0 & 358 & 514 & 658 & 824 & 828 & 618 & 638 & 512 & 452 & 384 & 333 \\
\hline 5.5 & 0 & 0 & 0 & 610 & 774 & 880 & 936 & 905 & 805 & 603 & 456 & 397 & 311 \\
\hline 6 & 0 & 0 & 0 & 711 & 952 & 974 & 1000 & 838 & 886 & 648 & 501 & 503 & 396 \\
\hline 6.5 & 0 & 0 & 0 & 788 & 1000 & 1000 & 1000 & 979 & 1000 & 727 & 577 & 435 & 424 \\
\hline 7 & 0 & 0 & 0 & 871 & 1000 & 1000 & 1000 & 1000 & 1000 & 959 & 748 & 574 & 472 \\
\hline
\end{tabular}

Table A9. Power matrix (in kW) for the wave energy converter Oyster [3]

\begin{tabular}{|c|c|c|c|c|c|c|c|c|c|}
\hline \multicolumn{10}{|c|}{ Power matrix (in kW) } \\
\hline \multirow{2}{*}{ Hs(m) } & \multicolumn{10}{|c|}{ Te(s) } \\
\cline { 2 - 11 } & $\mathbf{5}$ & $\mathbf{6}$ & $\mathbf{7}$ & $\mathbf{8}$ & $\mathbf{9}$ & $\mathbf{1 0}$ & $\mathbf{1 1}$ & $\mathbf{1 2}$ & $\mathbf{1 3}$ \\
\hline $\mathbf{0 . 5}$ & 0 & 0 & 0 & 0 & 0 & 0 & 1 & 3 & 3 \\
\hline $\mathbf{1}$ & 20 & 30 & 38 & 42 & 44 & 44 & 45 & 47 & 45 \\
\hline $\mathbf{1 . 5}$ & 80 & 85 & 92 & 97 & 102 & 103 & 104 & 100 & 104 \\
\hline $\mathbf{2}$ & 140 & 147 & 152 & 158 & 155 & 155 & 160 & 161 & 156 \\
\hline $\mathbf{2 . 5}$ & 192 & 197 & 208 & 202 & 203 & 209 & 211 & 201 & 204 \\
\hline $\mathbf{3}$ & 241 & 237 & 237 & 241 & 243 & 230 & 236 & 231 & 235 \\
\hline $\mathbf{3 . 5}$ & 0 & 271 & 272 & 269 & 268 & 267 & 270 & 260 & 260 \\
\hline $\mathbf{4}$ & 0 & 291 & 290 & 290 & 280 & 287 & 276 & 278 & 277 \\
\hline $\mathbf{4 . 5}$ & 0 & 291 & 290 & 290 & 280 & 287 & 276 & 278 & 277 \\
\hline $\mathbf{5}$ & 0 & 0 & 290 & 290 & 280 & 287 & 276 & 278 & 277 \\
\hline $\mathbf{5 . 5}$ & 0 & 0 & 290 & 290 & 280 & 287 & 276 & 278 & 277 \\
\hline $\mathbf{6}$ & 0 & 0 & 290 & 290 & 280 & 287 & 276 & 278 & 277 \\
\hline
\end{tabular}


Table A10. Power matrix (in kW) for the wave energy converter Aqua Buoy [31]

\begin{tabular}{|c|c|c|c|c|c|c|c|c|c|c|c|c|c|}
\hline \multicolumn{14}{|c|}{ Power matrix (in kW) } \\
\hline \multirow[b]{2}{*}{$\mathrm{Hs}(\mathrm{m})$} & \multicolumn{13}{|c|}{$\mathrm{Tp}(\mathrm{s})$} \\
\hline & 5 & 6 & 7 & 8 & 9 & 10 & 11 & 12 & 13 & 14 & 15 & 16 & 17 \\
\hline 1 & 0 & 0 & 8 & 11 & 12 & 11 & 10 & 8 & 7 & 0 & 0 & 0 & 0 \\
\hline 1.5 & 0 & 13 & 17 & 25 & 27 & 26 & 23 & 19 & 15 & 12 & 12 & 12 & 7 \\
\hline 2 & 0 & 24 & 30 & 44 & 49 & 47 & 41 & 34 & 28 & 23 & 23 & 23 & 12 \\
\hline 2.5 & 0 & 37 & 47 & 69 & 77 & 73 & 64 & 54 & 43 & 36 & 36 & 36 & 19 \\
\hline 3 & 0 & 54 & 68 & 99 & 111 & 106 & 92 & 77 & 63 & 51 & 51 & 51 & 27 \\
\hline 3.5 & 0 & 0 & 93 & 135 & 152 & 144 & 126 & 105 & 86 & 70 & 70 & 70 & 38 \\
\hline 4 & 0 & 0 & 0 & 122 & 176 & 198 & 173 & 164 & 137 & 112 & 91 & 91 & 49 \\
\hline 4.5 & 0 & 0 & 0 & 223 & 250 & 239 & 208 & 173 & 142 & 115 & 115 & 115 & 62 \\
\hline 5 & 0 & 0 & 0 & 250 & 250 & 250 & 250 & 214 & 175 & 142 & 142 & 142 & 77 \\
\hline 5.5 & 0 & 0 & 0 & 250 & 250 & 250 & 250 & 250 & 211 & 172 & 172 & 172 & 92 \\
\hline
\end{tabular}

Table A11. Power matrix (in kW) for the wave energy converter SSG [3]

\begin{tabular}{|c|c|c|c|c|c|c|c|c|c|c|c|c|c|c|}
\hline \multicolumn{15}{|c|}{ Power matrix (in kW) } \\
\hline \multirow[t]{2}{*}{$\mathrm{Hs}(\mathrm{m})$} & \multicolumn{14}{|c|}{$\mathrm{Te}(\mathrm{s})$} \\
\hline & 5 & 5.5 & 6 & 6.5 & 7 & 7.5 & 8 & 8.5 & 9 & 9.5 & 10 & 10.5 & 11 & 11.5 \\
\hline 0.5 & 99.00 & 109.000 & 119.000 & 129.000 & 139.000 & 149.000 & 159.000 & 169.000 & 179.000 & 189.000 & 198.000 & 208.000 & 218.000 & 228.000 \\
\hline 1 & 397.00 & 437.000 & 476.000 & 516.000 & 556.000 & 595.000 & 635.000 & 675.000 & 715.000 & 754.000 & 794.000 & 833.000 & 873.000 & 913.000 \\
\hline 1.5 & 893.00 & 982.000 & 1072.000 & 1161.000 & 1250.000 & 1340.000 & 1429.000 & 1518.000 & 1608.000 & 1697.000 & 1786.000 & 1875.000 & 1965.000 & 2054.000 \\
\hline 2 & 1588.00 & 1746.000 & 1905.000 & 2064.000 & 2223.000 & 2381.000 & 2540.000 & 2699.000 & 2858.000 & 3016.000 & 3175.000 & 3334.000 & 3493.000 & 3651.000 \\
\hline 2.5 & 2481.00 & 2729.000 & 2977.000 & 3225.000 & 3473.000 & 3721.000 & 3969.000 & 4217.000 & 4465.000 & 4713.000 & 4961.000 & 5209.000 & 5457.000 & 5705.000 \\
\hline 3 & 3572.000 & 3929.000 & 4287.000 & 4644.000 & 5001.000 & 5358.000 & 5715.000 & 6073.000 & 6430.000 & 6787.000 & 7144.000 & 7501.000 & 7859.000 & 8216.000 \\
\hline 3.5 & 4862.00 & 5348.000 & 5834.000 & 6.321 & 6807.000 & 7203.000 & 7779.000 & 8265.000 & 8751.000 & 9238.000 & 9724.000 & 10.210 & 10.695 & 11.183 \\
\hline 4 & 6350.00 & 6985.000 & 7620.000 & 8.256 & 8891.000 & 9526.000 & 10.161 & 10.796 & 11.431 & 12.066 & 12.701 & 13.336 & 13.971 & 14.606 \\
\hline 4.5 & 8037.00 & 8841.000 & 9645.000 & 10.448 & 11.252 & 12.056 & 12.860 & 13.663 & 14.467 & 15.271 & 16.074 & 16.878 & 17.682 & 18.486 \\
\hline 5 & 9923.00 & 10.915 & 11.907 & 12.899 & 13.892 & 14.884 & 15.876 & 16.868 & 17.860 & 18.853 & 19.845 & 20.000 & 20.000 & 20.000 \\
\hline 5.5 & 12.006 & 13.207 & 14.407 & 15.608 & 16.809 & 18.009 & 19.210 & 20.000 & 20.000 & 20.000 & 20.000 & 20.000 & 20.000 & 20.000 \\
\hline 6 & 14.288 & 15.717 & 17.146 & 18.575 & 20.000 & 20.000 & 20.000 & 20.000 & 20.000 & 20.000 & 20.000 & 20.000 & 20.000 & 20.000 \\
\hline 6.5 & 16.769 & 18.446 & 20.000 & 20.000 & 20.000 & 20.000 & 20.000 & 20.000 & 20.000 & 20.000 & 20.000 & 20.000 & 20.000 & 20.000 \\
\hline 7 & 19.448 & 20.000 & 20.000 & 20.000 & 20.000 & 20.000 & 20.000 & 20.000 & 20.000 & 20.000 & 20.000 & 20.000 & 20.000 & 20.000 \\
\hline 7.5 & 20.000 & 20.000 & 20.000 & 20.000 & 20.000 & 20.000 & 20.000 & 20.000 & 20.000 & 20.000 & 20.000 & 20.000 & 20.000 & 20.000 \\
\hline 8 & 20.000 & 20.000 & 20.000 & 20.000 & 20.000 & 20.000 & 20.000 & 20.000 & 20.000 & 20.000 & 20.000 & 20.000 & 20.000 & 20.000 \\
\hline
\end{tabular}




\section{APPENDIX B}

In this appendix, figures of the different WECs system used in this research are shown.

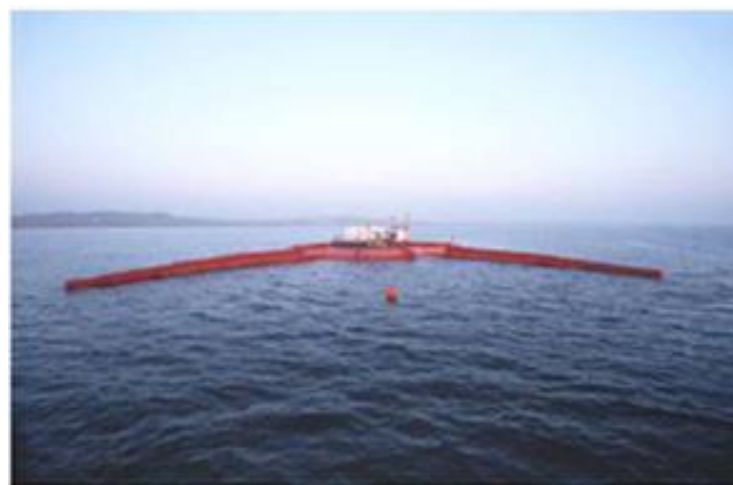

Fig. 7 Wave dragon [33]

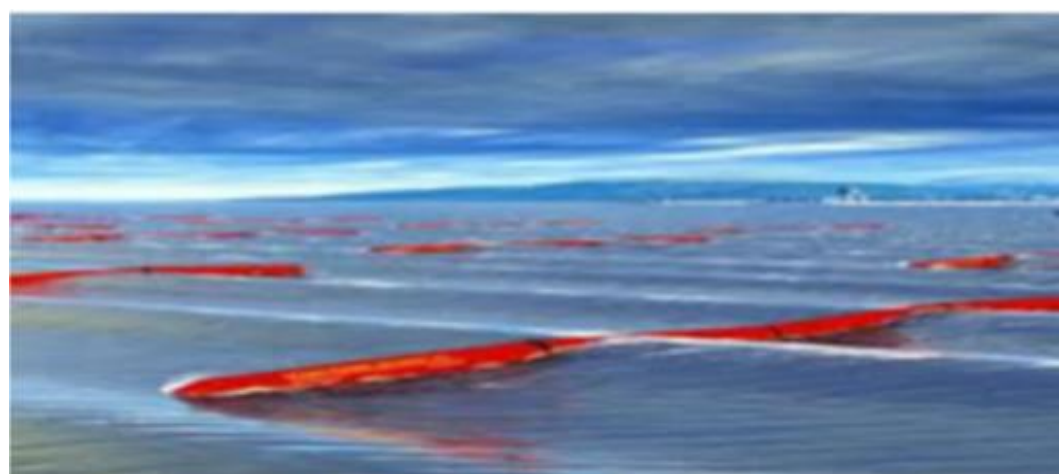

Fig. 8 Pelamis [34]

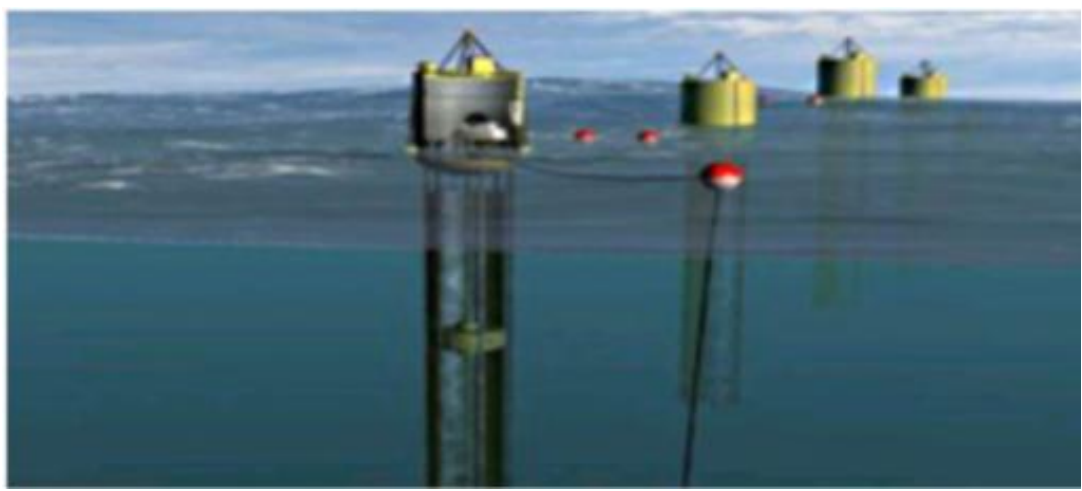

Fig. 9 AquaBuoy [35] 


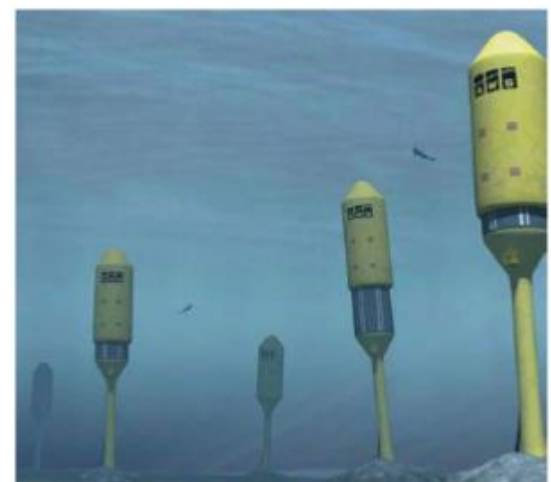

Fig. 10 Archimedes Wave Swing [36]

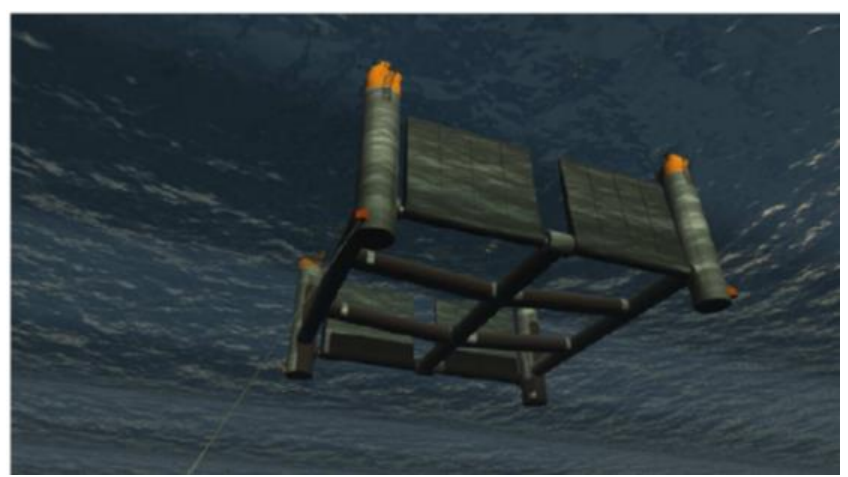

Fig. 11 Langlee [32]

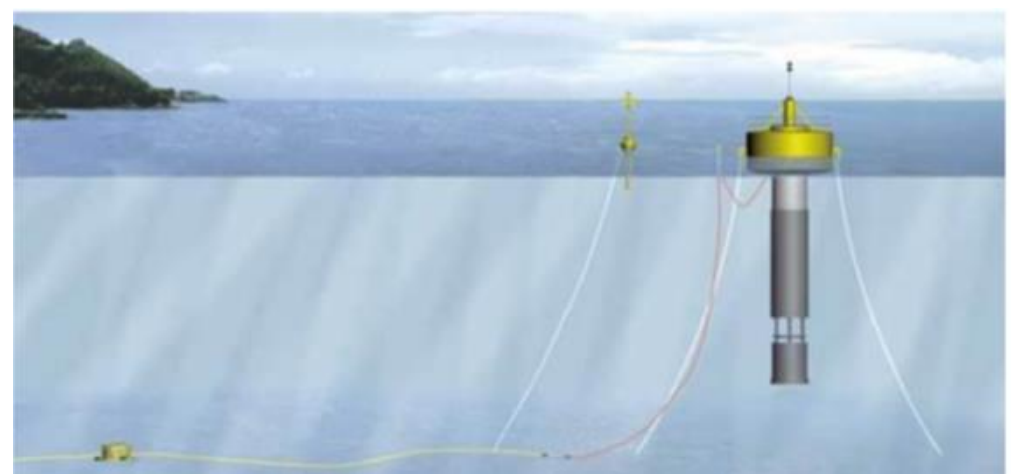

Fig. 12 Oceantec [37]

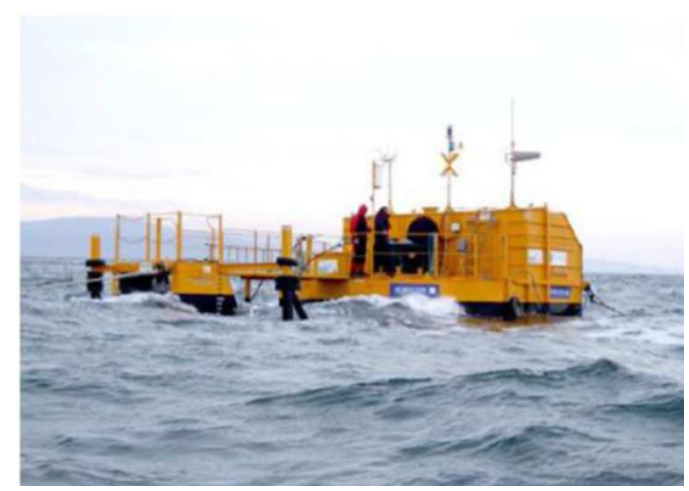

Fig. 13 OE buoy [32] 


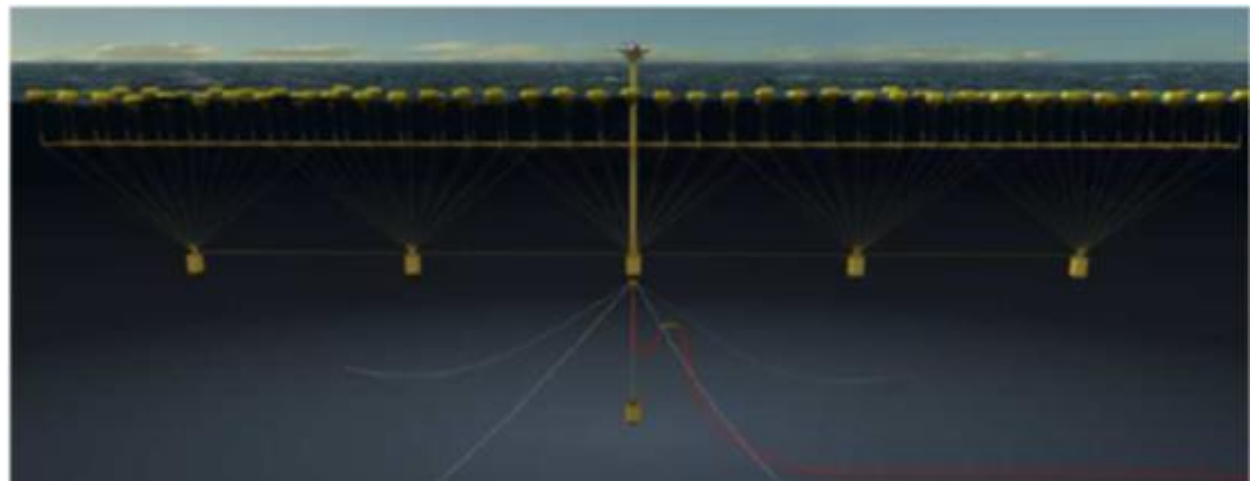

Fig. 14 Pontoon [32]

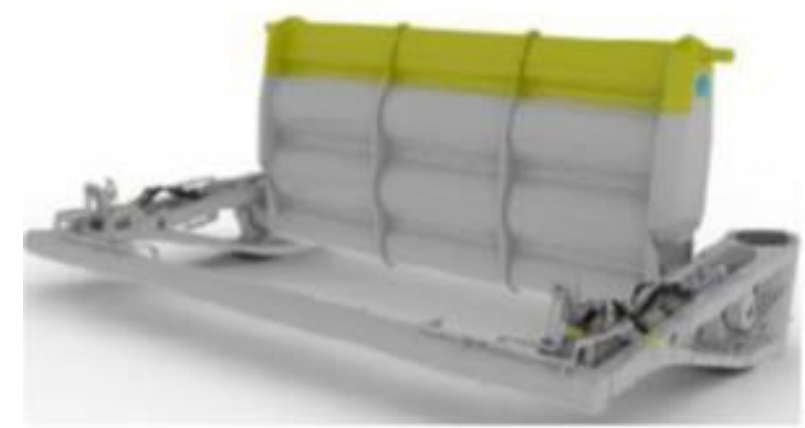

Fig. 15 Oyster [32]

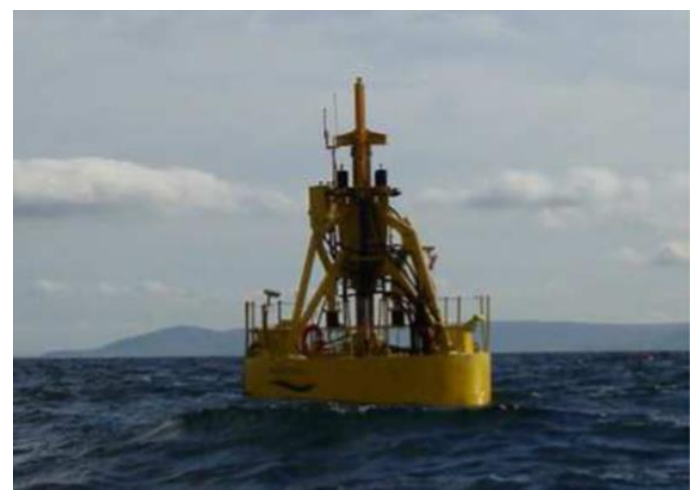

Fig. 16 Wavebob [32]

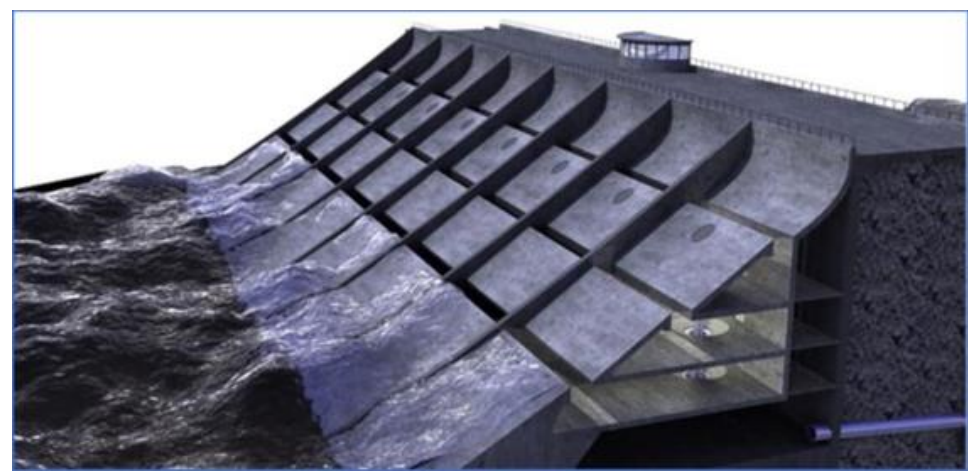

Fig. 17 SSG [38] 


\section{REFERENCES}

[1] Soares C. G., Bento, A. R., Gonçalves, M., Silva, D., Martinho, P., 2014. Numerical evaluation of the wave energy resource along the Atlantic European coast. Computers \& Geosciences, 71, 37-49. https://doi.org/10.1016/j.cageo.2014.03.008

[2] Silva, D., Bento, A. R., Martinho, P., Soares, C. G., 2015. High resolution local wave energy modelling for the Iberian Peninsula. Energy, 91,1099-1112; 94, 857-858. https://doi.org/10.1016/j.energy.2015.11.033

[3] Silva, D., Martinho, P., Soares, C. G., 2018. Wave energy distribution along the Portuguese continental coast based on a thirty three years hindcast. Renewable Energy, 127(4), 1067-1075. https://doi.org/10.1016/j.renene.2018.05.037

[4] Rusu, E., Pilar, P., Soares, C. G., 2008. Evaluation of the Wave Conditions in Madeira Archipelago with Spectral Models. Ocean Engineering, 35(13), 1357-1371. https://doi.org/10.1016/j.oceaneng.2008.05.007

[5] Iglesias, G., Carballo, R., 2011. Wave resource in El Hierro-an island towards energy self-sufficiency. Renewable Energy, 36, 689-698. https://doi.org/10.1016/j.renene.2010.08.021

[6] Rusu, L., Soares, C. G., 2012. Wave energy assessments in the Azores islands. Renewable Energy, 45, 183-196. https://doi.org/10.1016/i.renene.2012.02.027

[7] Sierra, J.P., González-Marco, D., Sospedra, J., Gironella, X., Mösso, C., Sánchez-Arcilla, A., 2013. Wave energy resource assessment in Lanzarote (Spain). Renewable Energy, 55, 480-489. https://doi.org/10.1016/j.renene.2013.01.004

[8] Gonçalves, M., Martinho, P., Soares, C. G., 2014. Assessment of wave energy in the Canary Islands. Renewable Energy, 68,774-784. https://doi.org/10.1016/j.renene.2014.03.017

[9] Ponce de León S., Orfila A., Simarro G., 2015. Wave energy in the Balearic Sea. Evolution from a 29 years spectral wave hindcast. Renewable Energy, 82, 1192-1200. https://doi.org/10.1016/j.renene.2015.07.076

[10] Bernardino, M., Rusu, L., Soares, C. G., 2017. Evaluation of the wave energy resources in the Cape Verde Islands. Renewable Energy, 101, 316-326. https://doi.org/10.1016/j.renene.2016.08.040

[11] Silva, D., Rusu, E., Soares, C. G., 2016. High-resolution wave energy assessment in shallow water accounting for tides. Energies, 9(9), 761-779. https://doi.org/10.3390/en9090761

[12] Rusu, E., Soares, C. G., 2013. Coastal Impact Induced by a Pelamis Wave Farm Operating in the Portuguese Nearshore. Renewable Energy, 58, 34-49. https://doi.org/10.1016/j.renene.2013.03.001

[13] Silva, D., Rusu, E., Soares, C. G., 2018. The effect of a wave energy farm protecting an aquaculture installation. Energies, 11(8), 2109. https://doi.org/10.3390/en11082109

[14] Monteforte, M., Re, C. L., Ferreri, G. B., 2015. Wave energy assessment in Sicily (Italy). Renewable Energy, 78, 276-287. https://doi.org/10.1016/j.renene.2015.01.006

[15] Farkas, A., Degiuli, N., Martić, I., 2019. Assessment of offshore wave energy potential in the Croatian part of the Adriatic sea and comparison with wind energy potential. Energies, 12(12), 2357. https://doi.org/10.3390/en12122357

[16] Bento, A. R., Martinho, P., Soares, C. G., 2018. Wave energy assessment for Northern Spain from a 33year hindcast. Renewable Energy, 127, 322-333. https://doi.org/10.1016/j.renene.2018.04.049

[17] Silva, D., Rusu, E., Soares, C. G., 2013. Evaluation of various technologies for wave energy conversion in the Portuguese nearshore. Energies, 6, 1344-1364. https://doi.org/10.3390/en6031344

[18] Andalusia Energy Agency, 2008. https://www.ideandalucia.es/portal/nodo-agencia-andaluza-de-laenergia/ accessed 21st December 2020.

[19] Statistics National Institute, 2008. https://www.ine.es/ accessed 21st December 2020.

[20] Puertos del Estado, 2008. http://www.puertos.es/ accessed 21st December 2020.

[21] Oceanor, 2009. https://www. Oceanor.com/ accessed 21st January 2021.

[22] Axystechnologies, 2009. https://axystechnologies.com/ accessed 21st January 2021.

[23] Soares, C. G., 2008. Hindcast of Dynamic Processes of the Ocean and Coastal Areas of Europe. Coastal Engineering, 55(11), 825-826. https://doi.org/10.1016/j.coastaleng.2008.02.007

[24] Meteorology Statal Agency, 2008. http://www.aemet.es/ accessed 21st December 2020.

[25] Pastor, J., Liu, Y., 2015. Wave Energy Resource Analysis for Use in Wave Energy Conversion. Journal of Offshore Mechanics and Arctic Engineering, 137, 011903-9. https://doi.org/10.1115/1.4028880 
[26] Hagerman, G., 2001. Southern New England Wave Energy Resource Potential. Building Energy, Boston, USA.

[27] Falnes, A., Kurniawan, A., 2015. Fundamental formulae for wave-energy conversion. Royal Society Open Science, 2, 1-34. https://doi.org/10.1098/rsos.140305

[28] Titah-Benbouzid, H., Benbouzid, M., 2015. An Up-to-Date Technologies Review and Evaluation of Wave Energy Converters. International Review of Electrical Engineering-IREE, 10(1), 52-61. https://doi.org/10.15866/iree.v10i1.5159

[29] Soares, C. G., Bhattacharjee, J., Tello, M., Pietra, L., 2012. Review and classification of Wave Energy Converters. Maritime Engineering and Technology. Taylor \& Francis Group. London, UK, 585-59.

[30] Falcao, A., 2010. Wave energy utilization: A review of the technologies. Renewable and Sustainable Energy Reviews, 14, 899-918. https://doi.org/10.1016/j.rser.2009.11.003

[31] Diaconu, S., Rusu, E., 2013. Evaluation of various WEC devices in the Romanian near shore. 13th Advances in Environment Technologies, Agriculture, Food and Animal Science, Brasov, Romani.

[32] Babarit, A., Hals, J., Muliawan, M., Kurniawan, A., Moan, T., Krokstad, J., 2012. Numerical benchmarking study of a selection of wave energy converters. Renewable Energy, 41, 44-63. https://doi.org/10.1016/j.renene.2011.10.002

[33] Wave Dragon, 2009. www.wavedragon.net accessed 21st January 2021.

[34] Pelamis, 2009. http://tinyurl.com/pelamis/ accessed 21st January 2021.

[35] AquaBuoy, 2009. www.inhibitant.com accessed 21st January 2021.

[36] Archimedes Wave Swing, 2009. http://tinyurl.com/archws1/ accessed 21st January 2021.

[37] Oceantec, 2008. www. Oceantec.es accessed 21st January 2021.

[38] Cascajo R., García E., Quiles E., Correcher A., Morant F., 2019. Integration of marine wave energy converters into seaports: A case study in the port of Valencia. Energies, 12(5), 787. https://doi.org/10.3390/en12050787

[39] Rusu E., 2014. Evaluation of the wave energy conversion efficiency in various coastal environments. Energies, 7, 4002-40018. https://doi.org/10.3390/en7064002

[40] Vannuchi V., Cappietti L., 2016. Wave energy assessment and performance estimation of state of the art wave energy converters in Italian hotspots. Sustainability, $8 \quad$ (12), 1300. https://doi.org/10.3390/su8121300

[41] Rusu E., Soares, C. G., 2012. Wave energy pattern around the Madeira Islands. Energy, 45, 771-785. https://doi.org/10.1016/j.energy.2012.07.013

[42] Bozzi S., Archetti R., Passoni G., 2014. Wave electricity production in Italian offshore: A preliminary investigation. Renewable Energy, 62, 407-416. https://doi.org/10.1016/j.renene.2013.07.030

Submitted: $\quad$ 24.11.2021. María José Legaz, mariajose.legaz@uca.es

Department of Sciences and Techniques of Navigation and Naval Construction, University of Cádiz, Cádiz, Spain

Accepted: $\quad$ 05.02.2022. Carlos Guedes Soares

Centre for Marine Technology and Ocean Engineering (CENTEC), Instituto Superior Técnico, Lisbon, Portugal 